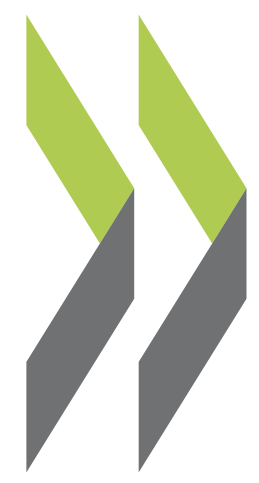

OECD Economics Department Working Papers No. 1045

Reforms for a Cleaner, Healthier Environment Sam Hill

in China 


\section{Unclassified}

ECO/WKP(2013)37

Organisation de Coopération et de Développement Économiques

Organisation for Economic Co-operation and Development

17-Apr-2013

ECONOMICS DEPARTMENT

English - Or. English

\section{REFORMS FOR A CLEANER, HEALTHIER ENVIRONMENT IN CHINA}

ECONOMICS DEPARTMENT WORKING PAPERS No. 1045

\section{By Sam Hill}

All Economics Department Working Papers are available through OECD's Internet website at http://www.oecd.org/eco/Workingpapers

JT03338313

Complete document available on OLIS in its original format

This document and any map included herein are without prejudice to the status of or sovereignty over any territory, to the delimitation of international frontiers and boundaries and to the name of any territory, city or area. 


\section{ABSTRACT/RÉSUMÉ \\ Reforms for a cleaner, healthier environment in China}

China's exceptional economic expansion has led to rising energy demand and pollution as well as other environmental pressures. Strong efforts by the government have moderated emissions of some types of air and water pollution from high levels but others, including greenhouse gas emissions, continue to rise. Poor air and water quality threaten human health, create other costs and reduce well-being. The 12th Five Year Plan aims at further reducing pollution and at other environmental improvements. To achieve these goals in a cost-effective manner wide-ranging reforms are needed. Reliance on command-and-control measures ought to make way gradually for well-implemented market-based approaches. Energy and water pricing need to be reformed to provide stronger incentives for end-users. So does pollution pricing. A carbon tax should be given serious consideration, especially if pilot carbon emissions trading schemes turn out to be difficult to implement. As well, stronger standards are needed, including for motor vehicles and fuels. Efforts to enhance environmental enforcement, particularly at the local level, will also be key to further progress.

This Working Paper relates to the 2013 OECD Economic Survey of China (www.oecd.org/eco/surveys/china).

JEL Classification: Q00, Q25, Q28, Q4, Q5, R48, I18

Keywords: air pollution, carbon tax, China, cities, emissions trading schemes, energy, environment, environmental taxation, health, pollution, renewable energy, water pollution.

\section{Des réformes pour assainir l'environnement en Chine}

L'expansion économique exceptionnelle de la Chine a entraîné une demande croissante d'énergie et une hausse de la pollution ainsi que d'autres pressions environnementales. Les efforts soutenus du gouvernement ont modéré les émissions de certains types de pollution de l'air et de l'eau à des niveaux élevés, mais d'autres, y compris les émissions de gaz à effet de serre continuent d'augmenter. La mauvaise qualité de l'eau et de l'air menace la santé humaine, crée des coûts supplémentaires et réduit le bien-être. Le $12^{\mathrm{e}}$ plan quinquennal vise à réduire la pollution et à améliorer l'environnement. Pour atteindre ces objectifs d'une manière rentable de vastes réformes sont nécessaires. La dépendance à l'égard des mesures de commandement et de contrôle devrait faire place progressivement à une bonne mise en œuvre des approches fondées sur le marché. Les prix de l'énergie et de l'eau doivent être réformés pour fournir des incitations plus fortes pour les utilisateurs finaux. Il en va de même pour la tarification de la pollution. Une taxe carbone devrait être sérieusement prise en considération, surtout si les régimes pilotes d'échange d'émissions de carbone se révèlent difficiles à mettre en œuvre. De plus, des normes plus strictes sont nécessaires, notamment pour les véhicules à moteur et les carburants. Les efforts visant à renforcer le respect de l'environnement, en particulier au niveau local, seront également essentiels à de nouveaux progrès.

Ce Document de travail se rapporte à l'Étude économique de la Chine de l'OCDE, 2013, (www.oecd.org/eco/etudes/chine).

Classification JEL: Q00, Q25, Q28, Q4, Q5, R48, I18

Mots-clés: pollution de l'air, taxe carbone, Chine, villes, systèmes d'échange d'émissions, énergie, environnement, fiscalité environnementale, santé, pollution, énergies renouvelables, pollution de l'eau.

(C) OECD (2013)

You can copy, download or print OECD content for your own use, and you can include excerpts from OECD publications, databases and multimedia products in your own documents, presentations, blogs, websites and teaching materials, provided that suitable acknowledgment of OECD as source and copyright owner is given. All requests for commercial use and translation rights should be submitted to rights@oecd.org. 


\section{TABLE OF CONTENTS}

Progress is being made but wide-ranging environmental challenges remain.......................................... 5

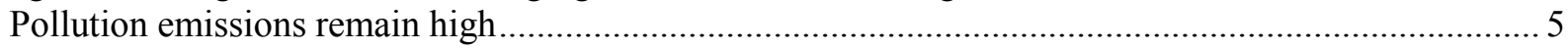

Several factors contribute to China's environmental challenges ..................................................... 10

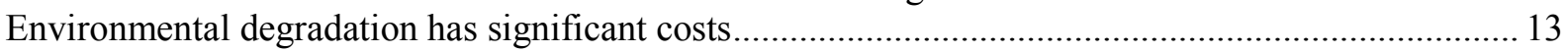

Addressing environmental priorities in the 12th FYP will require a broad policy response ................. 15

Market-oriented reforms will help improve resource efficiency....................................................... 20

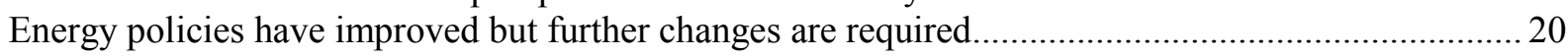

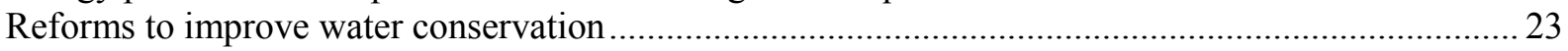

Appropriate pricing of pollution and support for renewable energy should form the cornerstone of

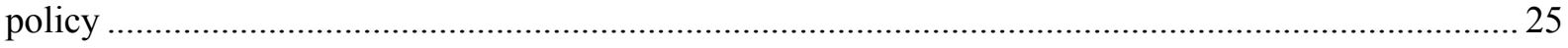

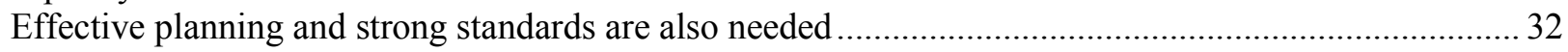

Well-planned cities are an important part of a long-term environmental and urbanisation strategy ..... 32

Better environmental standards and practices are needed to complement market-based approaches ... 33

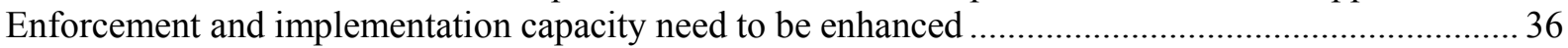

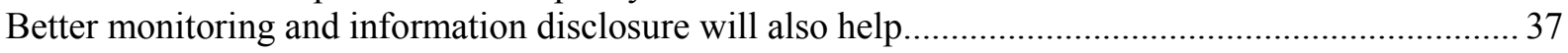

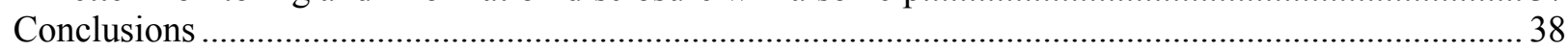

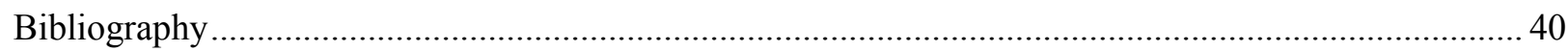

\section{Tables}

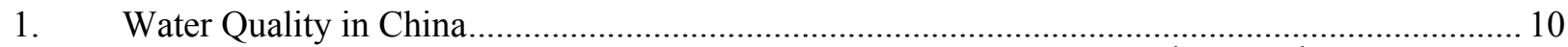

2. Summary of main environment related targets and outcomes for the $11^{\text {th }}$ and $12^{\text {th }} F$ FPs............ 16

\section{Figures}

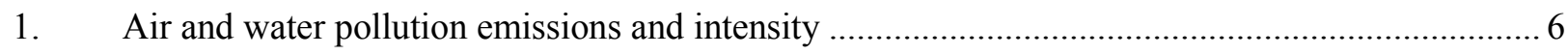

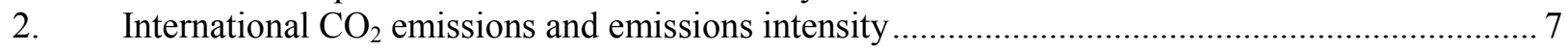

3. Distribution of particulate matter concentrations in cities......................................................... 8

4. Pollution levels in Beijing relative to WHO limits, January 2013 ........................................... 9

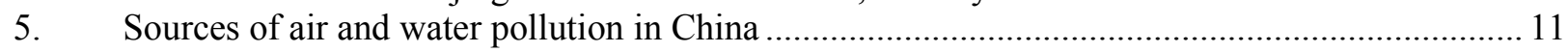

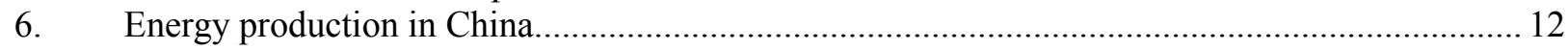

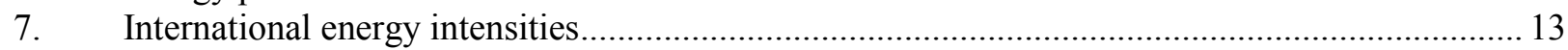

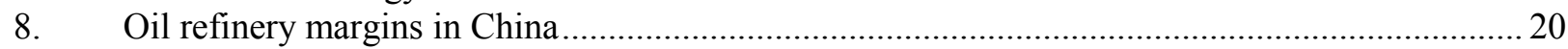

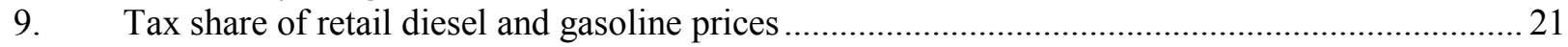

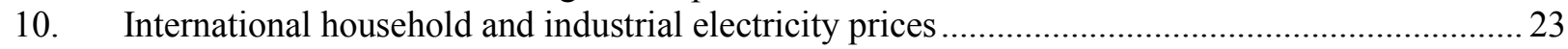

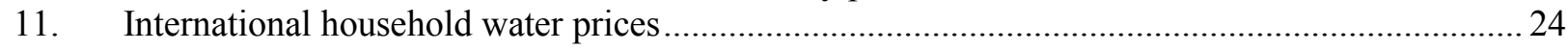

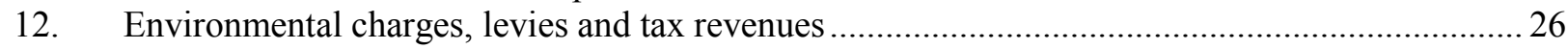

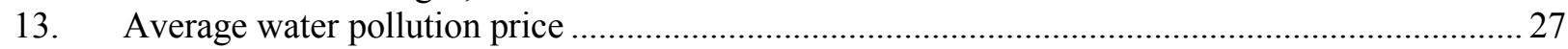

14. Impact of carbon pricing on the Chinese economy: a simulation ............................................ 31

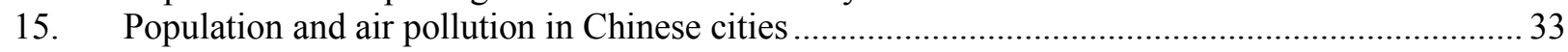

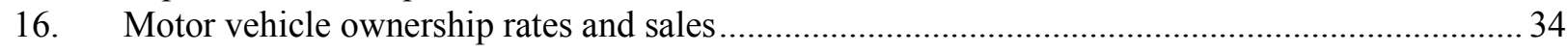

\section{Boxes}

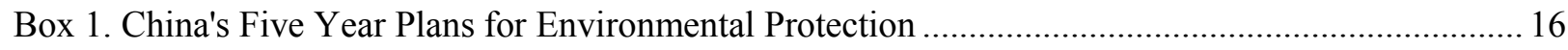

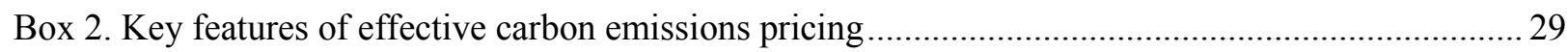

Box 3. Assessing the impact of carbon pricing in China …….............................................................. 31

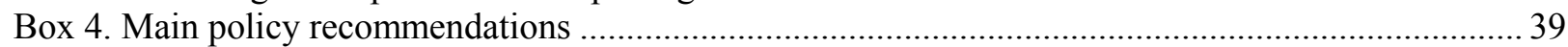


ECO/WKP(2013)37 
ECO/WKP(2013)37

\title{
REFORMS FOR A CLEANER, HEALTHIER ENVIRONMENT IN CHINA
}

\author{
Sam Hill ${ }^{1}$
}

As a rapidly growing middle-income country China faces a number of environmental challenges. Addressing these is an increasing priority for the government and under the auspices of targets laid out in the 11th Five Year Plan (FYP) some notable improvements have been achieved. Nevertheless, air and water pollution remains high. Water pollution is also exacerbated by water scarcity while a dependence on fossil fuels and rising energy demand poses a major challenge to controlling air pollution. These pressures impose significant health and other costs and reduce well-being. Often the poor suffer disproportionately and so environmental problems work against efforts by the government to reduce inequality. Environmental developments in China also have significant global repercussions, not least with respect to climate change.

Looking ahead, the government has set itself renewed environmental targets in the 12th FYP and this working paper examines how these and related goals can be achieved in a cost-effective manner. It first provides an overview of environmental trends and challenges, analyses their costs and recent policy responses. Market-based reforms to encourage energy and water conservation as well as how pollution pricing can be used more effectively are then examined. The complementary role of stronger standards and better enforcement are discussed before the paper concludes with a summary of policy recommendations.

\section{Progress is being made but wide-ranging environmental challenges remain}

\section{Pollution emissions remain high}

Against the backdrop of sustained high economic growth and rising living standards China has made progress in curbing some forms of pollution and achieved other environmental improvements. Progress was especially notable during the 11th FYP period (2006-10). Emissions of sulphur dioxide $\left(\mathrm{SO}_{2}\right)$, an important primary air pollutant, were decoupled from economic growth in the early 2000s and later declined in absolute terms (Figure 1A). Discharge of various types of water pollution also fell (Figure 1B). Total annual discharges of chemical oxygen demand (COD), which reflects the presence of organic and inorganic pollutants, were around 14\% lower in 2010 compared with a decade earlier, while discharges of ammonia nitrogen also declined. However, emissions of other pollutants continue to rise and overall pollution levels remain high. China is the single largest emitter of $\mathrm{SO}_{2}$, exceeding the combined emissions

1. Sam Hill was economist on the China desk in the OECD Economics Department when this working paper was prepared. It was originally produced as part of the OECD's 2013 Economic Survey of China (http://www.oecd.org/eco/surveys/economicsurveyofchina2013.htm), which was published under the authority of the OECD Secretary General. The author is grateful for valuable comments received on earlier drafts from Chinese officials, members of the Economic and Development Review Committee, Andrew Dean, Bob Ford, Vincent Koen, Richard Herd, Tomasz Kozluk, Nicola Brandt and Brenden Gillespie. Special thanks go to Thomas Chalaux for statistical assistance and to Nadine Dufour and Pascal Halim for editorial support. The views expressed in this paper do not necessarily reflect those of the OECD, of the Chinese authorities or of the OECD member countries. 
of the United States and the European Union. Chinese emissions of nitrous oxides (NOx), another important primary air pollutant, have continued to climb in recent years and exceed United States emissions by a considerable margin. Although per capita emissions of $\mathrm{SO}_{2}$ and $\mathrm{NOx}$ are lower, emissions relative to GDP, an indicator of environmental efficiency, are high compared with large and medium-sized OECD countries (Figure 1C).

Figure 1. Air and water pollution emissions and intensity

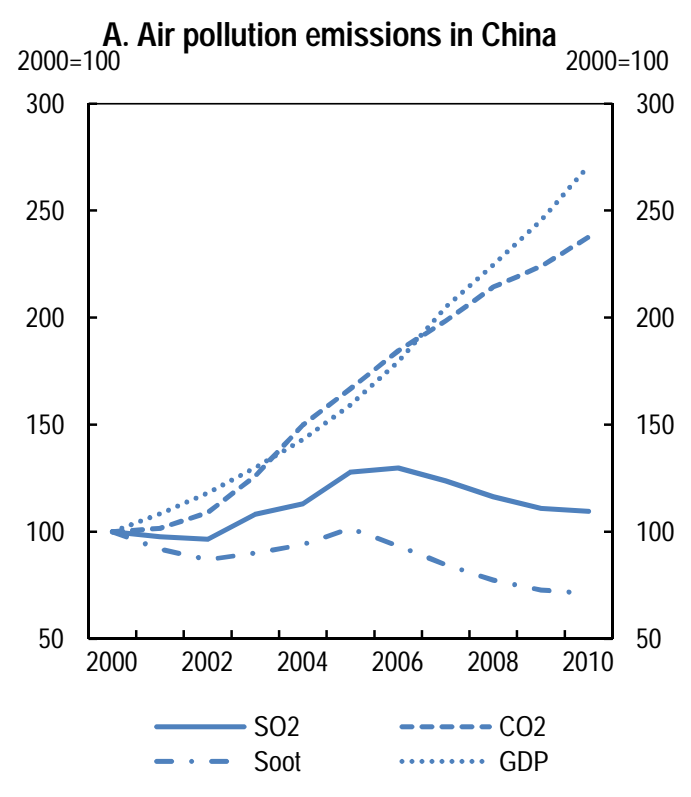

\section{B. Water pollution emissions in China}
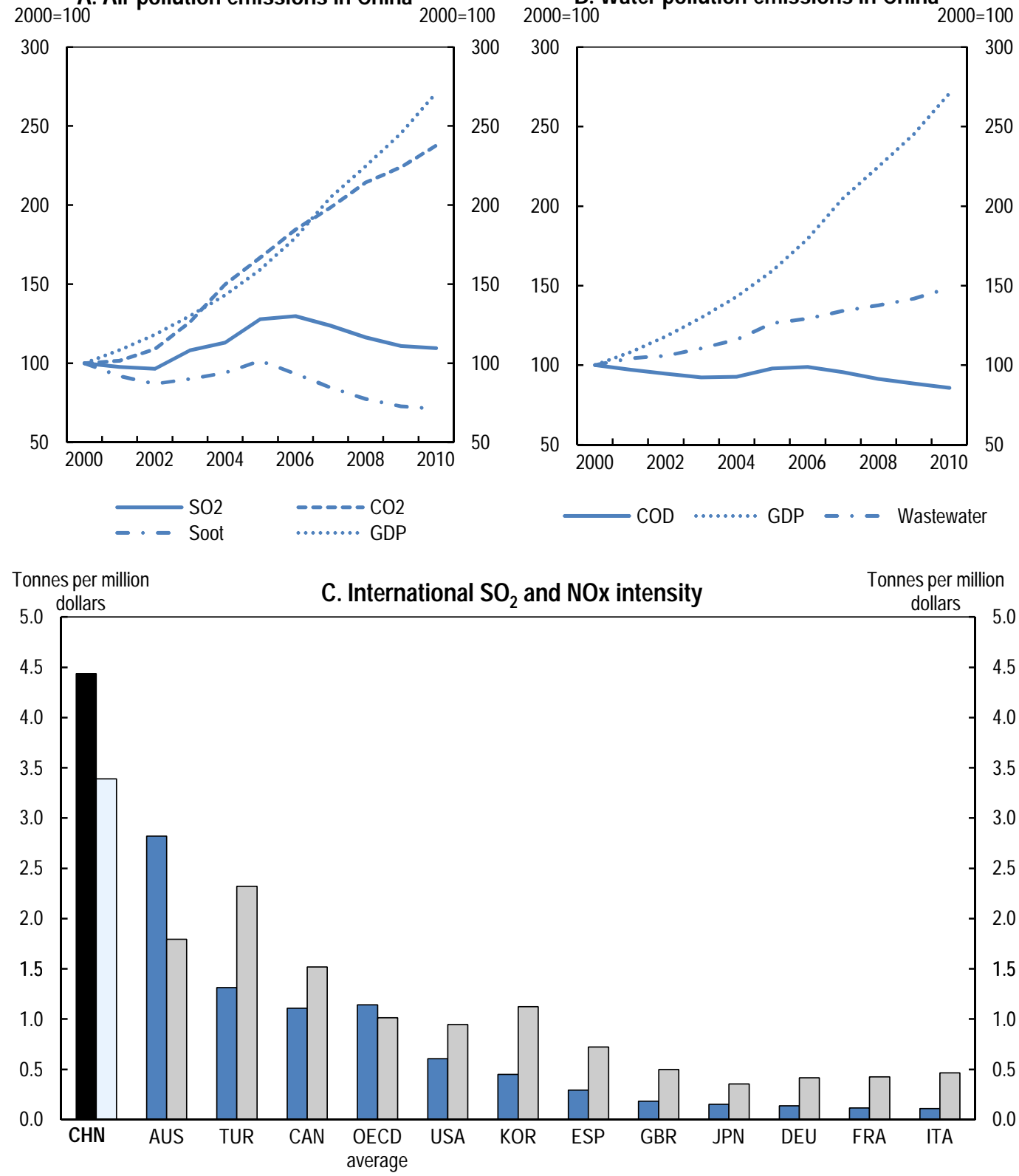

$\square$ SO2 intensity $\square$ NOX intensity

Note: Wastewater and COD includes industrial and household sources. Pollution intensity refers to 2010 or most recent observation. Source: CEIC, OECD and NBS-MEP (2011).

Emissions of $\mathrm{SO}_{2}$ and NOx contribute to secondary pollutants, including ground-level ozone and particulate matter, while nitrogen compounds from NOx contribute to eutrophication in waterways and the 
broader ecosystem. Together they cause acid rain, which affects aquatic life and damages crops and other vegetation as well as materials including building exteriors. Though the incidence of acid rain in China has declined somewhat in recent years, it remains a serious concern. In 2011 the government estimated that over $10 \%$ of China's landmass was affected, including farmlands and densely populated areas along the Yangtze River and in the South-East (MEP, 2012). In addition, almost half of a sample of 468 monitored cities was reported to have experienced frequent bouts of acid rain.

Official data on emissions of other important primary air pollutants such as carbon monoxide (CO), volatile organic compounds (VOCs), a precursor of ground level ozone, and black carbon, a form of particulate matter stemming from the incomplete combustion of fossil fuels, is scarce. However, independent studies relying on inventory methods to estimate emissions using fuel consumption and other data indicate emissions of these pollutants are also high by international standards. An estimate of total VOC emissions by Cao et al. (2011) compares unfavourably with many large OECD countries while on their estimates $\mathrm{CO}$ emissions far exceed those in the United States. In addition, recent estimates of Chinese emissions of black compiled by Qin and Xie (2012) are far greater than slightly more dated estimates for the United States (EPA, 2012).

China was the largest emitter of greenhouse gases (GHG) by 2005 and of energy-related $\mathrm{CO}_{2}$ by 2007 (IEA, 2012a). Though Chinese emissions of carbon dioxide $\left(\mathrm{CO}_{2}\right)$, the largest component of global GHG, have decoupled from GDP growth in recent years, they have continued to rise fast and reached almost 7 billion tonnes, around one quarter of the global total, in 2009 (Figure 2). Historically, GHG emissions from China were much lower than those of the advanced economies so that China's contribution to atmospheric concentrations today is smaller than that of many advanced economies. In addition, as many emissions are generated during the process of producing goods which are exported, consumption-based measures of $\mathrm{CO}_{2}$ emissions for China are significantly lower than production-based estimates (while the reverse is true for many OECD countries) (Nakano et al., 2009). China's per-capita emissions also continue to trail OECD countries but emissions intensity is well above OECD levels (Figure 2).

Figure 2. International $\mathrm{CO}_{2}$ emissions and emissions intensity

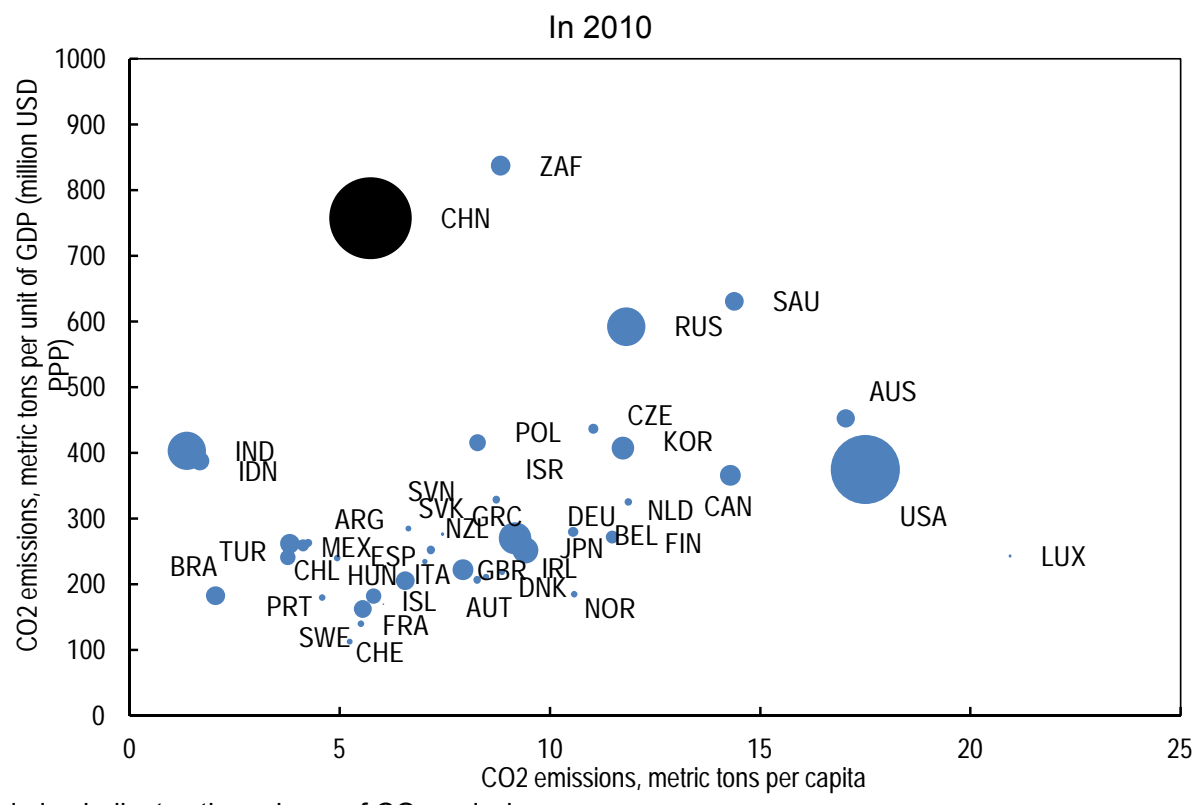

Note: The size of circles indicates the volume of $\mathrm{CO}_{2}$ emissions.

Source: OECD. 
As a consequence, air quality in Chinese cities, as well as many regions, is often poor. Across a number of major cities concentrations of air pollutants most closely monitored by the authorities including $\mathrm{SO}_{2}$, NOx and large particulate matter (PM10), which is particularly harmful to human health are high. In 2010, in 31 major Chinese cities including Beijing, other provincial-level cities and provincial capitals, the ambient concentration of PM10 averaged around $95 \mu \mathrm{g} / \mathrm{m}^{3}$, slightly lower than in 2005 but still well above the World Health Organisation (WHO) guidelines of $20 \mu \mathrm{g} / \mathrm{m}^{3}$. It also exceeds the WHO interim target level 1 of $70 \mu \mathrm{g} / \mathrm{m}^{3}$, a level associated with an approximately $15 \%$ higher long-term mortality risk relative to the guidelines level. Average NOx concentrations are also high in Chinese cities, at around the WHO guideline limits of $40 \mu \mathrm{g} / \mathrm{m}^{3}$. Moreover, as noted above, NOx emissions have risen in recent years and this is reflected in the air quality of cities where average NOx concentrations rose over $5 \%$ between 2005 and 2010. Urban air quality in China also compares poorly internationally, with concentrations of PM10 invariably higher than those in OECD and other middle-income countries (Figure 3).

Figure 3. Distribution of particulate matter concentrations in cities

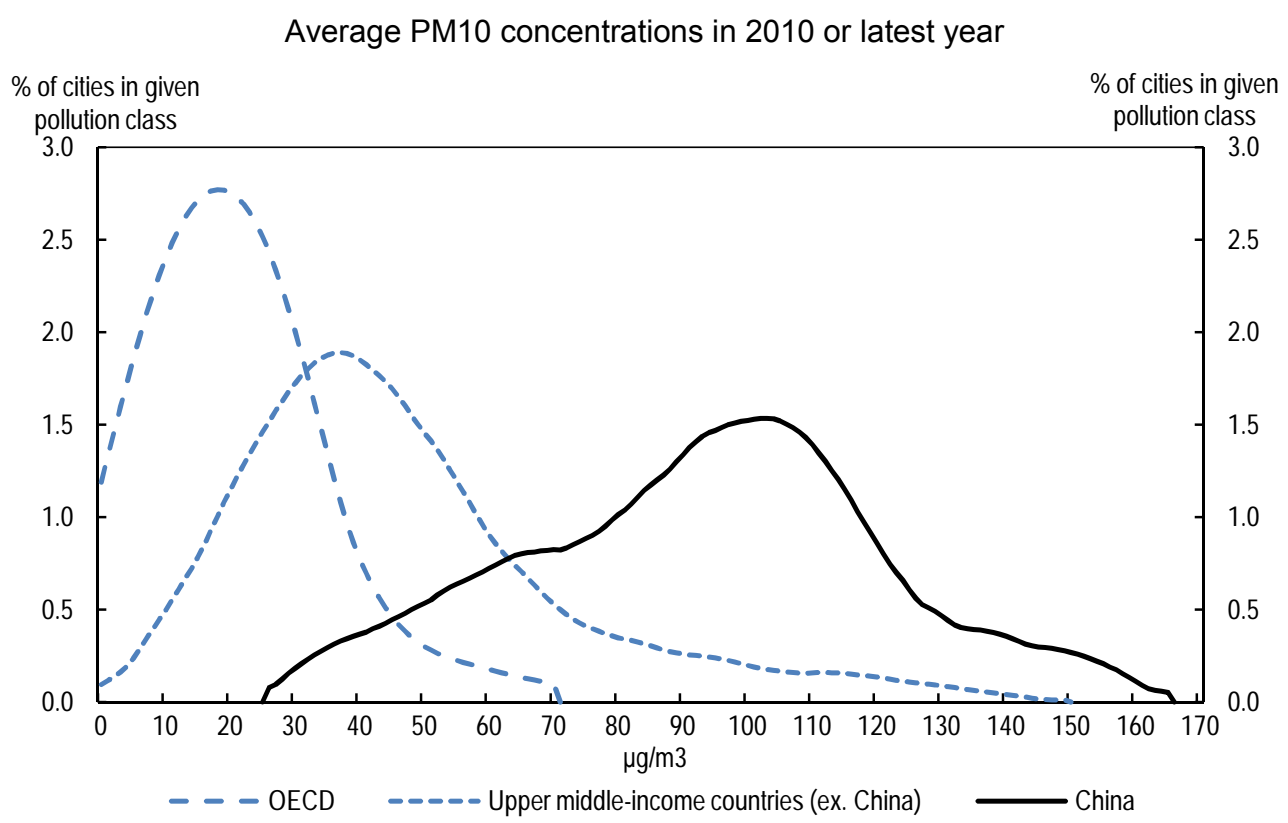

Note: Distributions are derived from kernel density estimates which are based on a sample of 32 cities for China. Source: WHO and China Statistical Yearbook.

Average annual figures obscure periods of even higher pollution in Chinese cities. In Beijing, over the winter of 2007-08, NOx pollution, around two thirds of which came from mobile sources, averaged seven times the WHO hourly guidelines. Pollution levels exhibited a saw-tooth pattern with peaks corresponding to periods when winds were from the south or south-east east pushing pollution towards the mountains to the north and north-west of the city, so preventing it from being blown away (Lin et al., 2011). A severe air pollution peak also occurred in January 2013. Unofficial data show that during this period the 24-hour concentration level of small particulate matter (PM2.5) averaged nine times the WHO safe exposure level and ozone levels also far exceeded WHO limits (Figure 4). 
Figure 4. Pollution levels in Beijing relative to WHO limits, January 2013

PM2.5 measured as a 24 hour average, ozone measured as an 8 hour average

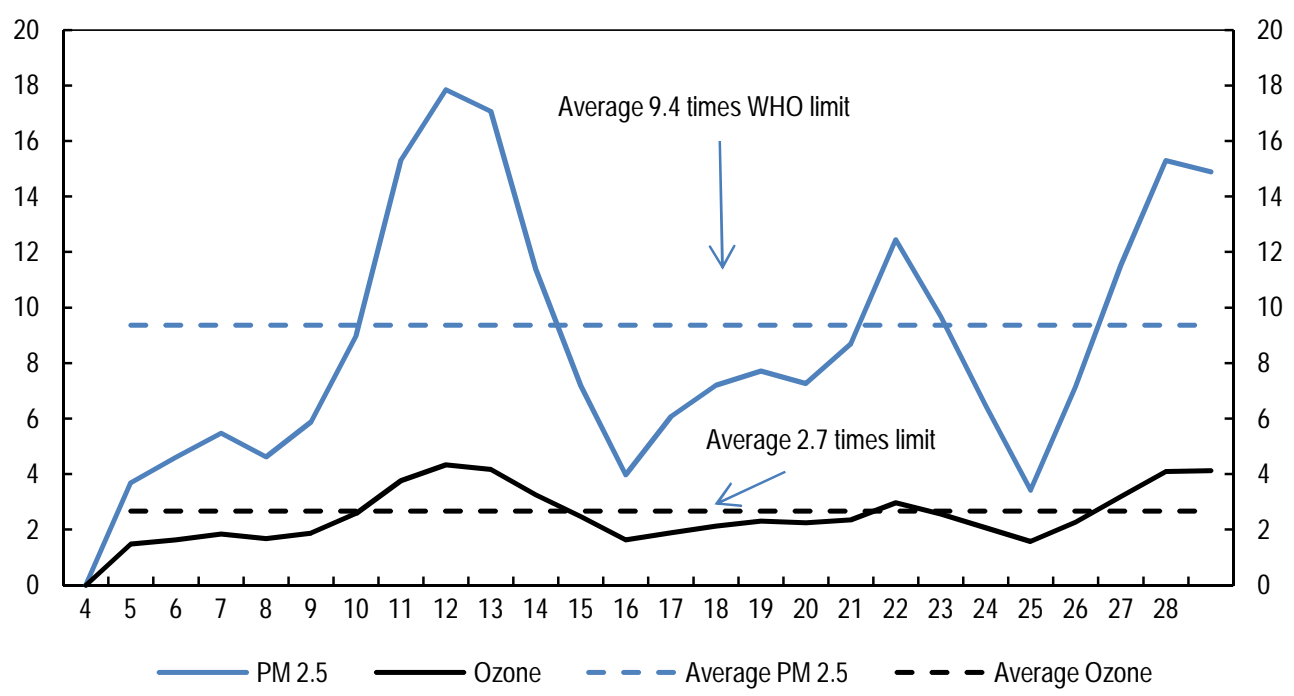

Source: Twiitter.com/BeijingAir.

Note: the data come from one monitoring station in central Beijing; however the Vice-Minister of Environmental Protection has stated that the figures from this station are roughly representative of the whole of Beijing $(\mathrm{Wu}, 2012 \mathrm{a})$.

While water quality has improved somewhat in recent years, reflecting declining pollution discharges, China's rivers and lakes continue to suffer from widespread and often severe pollution. As in other countries, China uses a grading system for monitoring and reporting the quality of freshwater across the country, with grade I water the highest quality and grade V-plus the worst. Water meeting at least grade II is deemed useable for drinking and water quality grade IV or worse inappropriate for contact with human skin. On this grading system, in 2011, out of 469 monitored sections of China's key national river basins, fewer than $40 \%$ were assessed as grade IV or worse, down from $54 \%$ in 2006 . The situation remains especially serious for major rivers in the north of the country which pass through large cities, including the Huaihe and Liaohe, where well over half of monitored sections were deemed to be grade IV or worse (Table 1). Recent data confirm that other parts of the freshwater system also suffer from serious pollution, with $85 \%$ of lakes deemed to have water quality grade IV or worse and over half of all lakes and reservoirs assessed as suffering from eutrophication.

Some sections of coastal waters are also heavily polluted. For marine areas a separate four plus one grading system is used to assess water quality with grade I the most pristine, grade IV the most polluted and water meeting grade II standard deemed appropriate for bathing. Coastal water quality along the three main seas monitored varies considerably. Along the Yellow Sea, in the north of the country, $83 \%$ of areas monitored reached the grade II standard. In contrast, over $60 \%$ of coastal areas of the East China Sea, to the south, failed to meet this grade. Coastal areas around some heavily populated sub-regions, including Bohai Bay, were also found to be heavily polluted. Official monitoring of water quality near river deltas underscores the impact of upstream pollution on coastal water quality, with over half of the monitored sections of rivers flowing into the East China Sea judged to be grade IV or worse on the freshwater grading system. 
Table 1. Water quality in China

In per cent, in 2011

\begin{tabular}{lccc}
\hline & Grade I-III & Grade IV-V & Grade V-plus \\
\cline { 2 - 4 } Major river systems & & & \\
Yangtze & 80.9 & 13.8 & 5.3 \\
Yellow & 69.8 & 11.6 & 18.6 \\
Pearl & 84.8 & 12.2 & 3.0 \\
Songhua & 45.2 & 40.5 & 14.3 \\
Huaihe & 41.9 & 43.0 & 15.1 \\
Haihe & 31.7 & 30.2 & 38.1 \\
Liaohe & 40.5 & 48.7 & 10.8 \\
National & $\mathbf{6 1 . 0}$ & $\mathbf{2 5 . 3}$ & $\mathbf{1 3 . 7}$ \\
& & & \\
Major lakes and reservoirs & 17.6 & 70.6 & 11.8 \\
Lakes & 88.9 & 11.1 & Not applicable \\
Reservoirs & & & \\
& Grade I-II & Grade III-IV & Worse than \\
& & & grade IV \\
Coastal areas & 83.3 & 16.7 & 0.0 \\
Yellow Sea & 36.9 & 23.1 & 40.0 \\
East China Sea & 78.6 & 13.6 & 7.8 \\
South China Sea & & &
\end{tabular}

Note: For river systems and coastal areas figures refer to the proportion of water monitoring stations meeting a particular water quality grade. For lakes and reservoirs an overall assessment is given to each water body. A five plus one grade system applies to the freshwater system and a four plus one system to coastal areas, with a lower grade indicating lower levels of pollution.

Source: MEP (2012).

Less systematic environmental monitoring makes an accurate assessment of conditions in rural areas difficult. However, in 2011 the Ministry for Environmental Protection (MEP) undertook a trial to assess air, soil and water quality in a sample of 364 villages. The results suggest that wide-ranging environmental pressures are not confined to cities, with a sizeable proportion of the villages surveyed failing to meet air and soil standards (Xiaoqing, 2012). This is consistent with studies showing significant pollution spillovers from cities into surrounding areas as well as high levels of pollution coming from rural areas themselves (Cao et al., 2006; Suthawaree et al., 2012; Xu et al., 2011; Yang et al., 2012). Likewise, rivers can transport pollution over large distances such that populations living in areas without high concentrations of heavily polluting industries may be exposed to upstream activities as well as environmental accidents which continue to pose a serious threat (He et al., 2012; Zhang and Zheng, 2012). Data on air quality assessed using satellite imagery confirm that the challenge of severe air pollution highlighted from in situ monitoring stations extends to rural areas (OECD, 2011a). Indeed, an overwhelming proportion of the national population was deemed to be exposed to PM2.5 levels in excess of WHO guidelines.

\section{Several factors contribute to China's environmental challenges}

China's environmental challenges stem from a range of factors, not least the sheer pace of economic expansion and associated resource demand growth, as well as underlying production and consumption patterns. By international and historical standards the manufacturing and investment shares of the economy are large, implying that economic activity has been focussed in more resource-intensive and heavilypolluting sectors. More specifically, high volumes of pollution originate from a range of point and nonpoint sources (Figure 5). Electricity generation and heating account for just under half of all $\mathrm{SO}_{2}$ emissions and just over half of NOx emissions. Other industrial sectors account for a further $40 \%$ of $\mathrm{SO}_{2}$ and almost $30 \%$ of NOx emissions, with especially large contributions from heavy industry including metal smelting and mineral processing. These same industries also account for a sizeable share of industrial smoke and soot emissions. Households directly account for around $15 \%$ of $\mathrm{SO}_{2}$ emissions and a much smaller 
proportion of NOx emissions, while motor vehicles produce around $15 \%$ of NOx emissions. In contrast, just under $40 \%$ of COD and almost $60 \%$ of ammonia nitrogen discharges come from households while agriculture contributes approximately another 50\% and 30\% of total COD and ammonia nitrogen discharges respectively. The industrial sector contribution to these pollutants is far smaller, with less than $15 \%$ of both COD and ammonia nitrogen discharges. However, a small number of industries including mining, metal processing and chemical production, account for most heavy metal discharges.

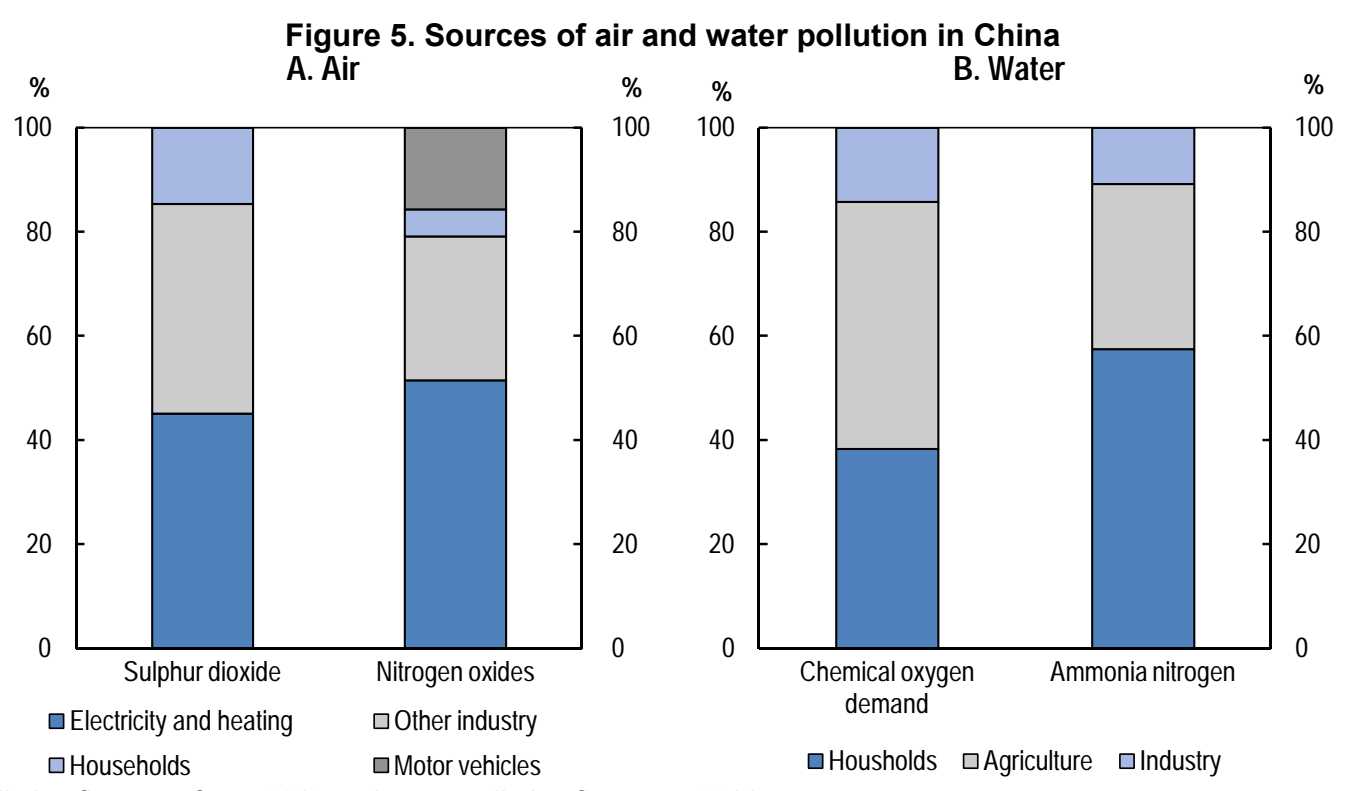

Note: Air pollution figures refer to 2010 and water pollution figures to 2011.

Source: MEP (2011b) and MEP (2012).

Sizeable air pollution emissions from energy production and industry reflect China's growing energy demand and supply structure, which continues to be dominated by coal for electricity production and direct use by industry in furnaces and boilers. China has one of the world's largest recoverable coal reserves and is the largest coal consumer and producer. In 2011, coal accounted for around $78 \%$ of total energy production, one of the highest shares of any major economy. Renewable and nuclear energy as well as cleaner fossil fuels, notably natural gas, have all expanded very quickly. In recent years China along with the United States has led global renewable energy investment and installed wind capacity has risen from almost nothing in the early 2000s to the world's largest (Pew, 2012). Photovoltaic and other solar capacity has also taken off, with China accounting for the majority of the global expansion in installed solar water heater capacity during the 2000s and half of world capacity by 2009 (IEA, 2011a). The 12th FYP targeted the installation of $5 \mathrm{GW}$ of solar energy capacity by 2015 . This initial target has been raised several times and in January 2013 the government announced that it expected $35 \mathrm{GW}$ of solar power to be installed by 2015. However, not all of the expansion in renewable energy capacity has been efficient, particularly in the wind sector: most capacity is located in northern regions, where weather conditions are conducive to wind power generation but which are distant from major sources of demand along the coast. Owing to this mismatch and problems with grid connectivity only around $70 \%$ of installed wind capacity had been connected to the grid in 2010 ( $\mathrm{Ni}$ and Yang, 2012). Some of the problems have been resolved since then with better planning. The State Electricity Regulatory Commission estimates that on average only $16 \%$ of wind electricity was lost due to curtailment problems in 2012.

Despite the impressive expansion in renewable and nuclear power, shares of these alternative energy sources remain small, at under $10 \%$ of total production in 2011 and with hydropower accounting for much of this. Indeed the share of coal in primary energy production has risen since the early 2000 s as the 
contribution from oil declined (Figure 6). Aside from emitting large quantities of primary air pollutants such as $\mathrm{SO}_{2}$ and NOx, coal-powered generators produce large quantities of mercury as well as airborne dust and soot and inhalable primary particulate matter. There are other adverse consequences from the current heavy reliance on coal. Though safety has improved the coal mining industry continues to be plagued by accidents. Coal mining also consumes large quantities of water and coal washing, while beneficial for reducing $\mathrm{SO}_{2}$, contributes to water pollution.

Figure 6. Energy production in China

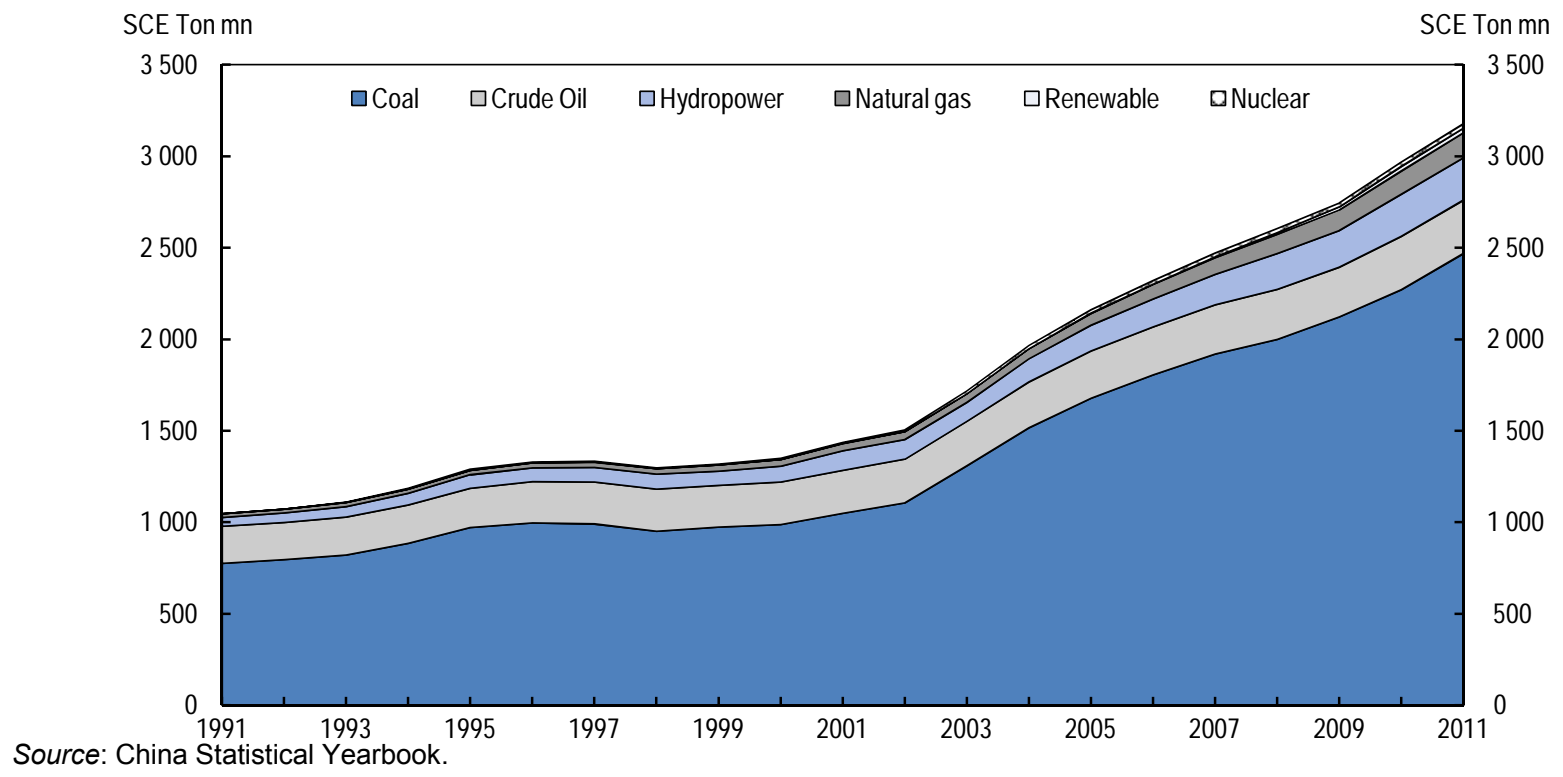

\section{Resource inefficiency compounds problems}

China has achieved major progress in energy efficiency over the past two decades but there is room for further progress. Improvements were particularly rapid during the 1990 s before being partially reversed in the early 2000s. This led to authorities redoubling efforts and targeting a stringent $20 \%$ improvement in energy efficiency during the 11th FYP, which was almost achieved. Even so, energy use continued to rise fast and China overtook the United States as the world's largest energy consumer in 2009 (IEA, 2010). China also remains less energy efficient than most OECD countries and some other large emerging economies (Figure 7). Most of the energy efficiency gains thus far are due to improvements within sectors rather than from rebalancing towards lower energy sectors (Wu, 2012b). In general, energy efficiency is highest in the more economically advanced regions of the country and national improvements partly reflect inefficient provinces converging towards better performing regions.

Improving water efficiency is also imperative, with relative water scarcity in China compounding water pollution problems. Per-capita renewable water resources, which reflect precipitation less losses due to evaporation, amount to around $2080 \mathrm{~m}^{3}$ in China, higher than in India but much lower than in a number of other sizeable countries. Moreover, rainfall is highly uneven across China, with much of the interior of the country and densely populated Northern provinces suffering very low rainfall. Indeed, the major river basins in the south, including the Yangtze and Pearl, capture around $80 \%$ of the country's total precipitation. In drier regions there is a heavy reliance on groundwater which is being extracted faster than it can be naturally replenished, resulting in declining water tables and land subsidence in cities and, for farmers and households without access to piped water, larger outlays for digging deeper wells (Gleik, 2009). 
Figure 7. International energy intensities

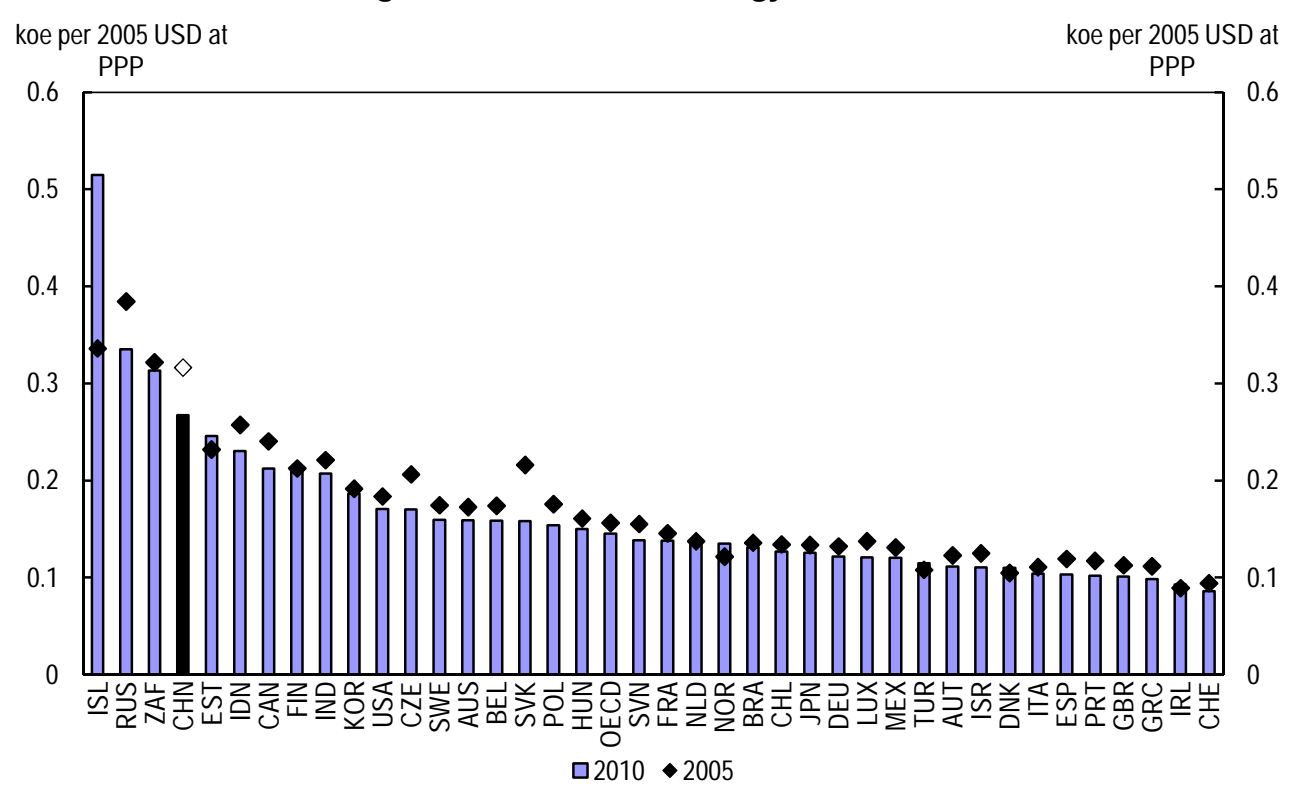

Source: OECD and IEA.

To address water shortages the government has invested heavily in water infrastructure projects, including agricultural irrigation. These and other measures have helped achieve significant improvements in water efficiency, enabling the economy to maintain strong growth with little increase in aggregate water consumption (Medianu and Whalley, 2012). In general, therefore, water infrastructure projects have represented a sound investment. However, some of them have been very costly financially and ecologically, including the largest scheme, the South-North Water Transfer Project. This massive undertaking is to link several of the nation's largest rivers and divert water from high rainfall areas in the south to dry and densely populated agricultural and urban areas in the north, including Beijing (Freeman, 2011).

\section{Environmental degradation has significant costs}

Environmental degradation has major economic and broader costs. Exposure to heavily polluted outdoor air and hazardous chemicals as well as the consumption of unsafe drinking water can damage health through many channels. Climate change may also entail sizeable costs, notably through changes in infectious diseases and weather. Indeed, Chinese cities are among the most exposed in the world to coastal flooding associated with climate change (Nicholls et al., 2008). General increases in temperatures can magnify the adverse effects of air pollution on health (Kan, 2011). Indoor air pollution generated from burning biomass fuel, which is still widely used in rural China, also harms health (Baumgartner et al., 2011). China has amongst the highest incidence of premature mortality due to outdoor PM exposure and this could worsen without policy action (OECD, 2012a). At a more local level, in recent years there have been reports of serious health threats related to pollution across the country (Jianrong, 2011; Economy, 2010). These have highlighted cases of elevated exposure and in some cases high blood concentrations of pollutants, such as lead, threats to drinking water safety and high localised incidences of disease including cancer.

Assessing the costs associated with environmental degradation can help gauge the merits of investing in pollution mitigation or taking other related actions. However, estimating these various costs can be difficult, especially those relating to human health. As there is no readily observable price for health or a human life, these must be valued indirectly. Two common methods are the willingness to pay approach and the human capital approach. In the first, estimates of a statistical value of life are calculated based on a 
person's willingness to pay in order to marginally reduce the probability of death. The cost of morbidity can be assessed using the same principle, which yields an indirect cost of illness. The human capital approach instead values life on the basis of forgone earnings due to premature death.

Recent estimates suggest the economic costs of environmental degradation in China are high, warranting a strong policy response. Combined health costs from PM and water pollution reached nearly $4 \%$ of GNI by the late 2000s (World Bank-DRC, 2012). The cost of $\mathrm{CO}_{2}$ emissions, imputed using a fixed price for carbon emissions, together with material damage from air pollution and soil nutrient depletion adds some $2.5 \%$ of GNI. Incorporating additional costs associated with energy and mineral depletion brings the total costs of environmental degradation to around $9 \%$ of GNI. A separate study, which incorporates the impact of cumulative exposure to air pollution rather than applying static analysis, estimates that health related costs of pollution alone were around 6\% of GDP in the mid-2000s (Matus et al., 2012). In this study the cost of pollution is also reported to have risen over time, as urbanisation sees more people exposed to heavily polluted air and as rising incomes increase the monetary value of health damages. However, as pollution levels have been relatively stable and there has been a strong sustained expansion of the economy, pollution costs as a share of GDP have declined.

Empirical analysis has examined the link between surface water quality and digestive cancers, highlighting the strong links between water pollution and health in China, as well as the large gains from efforts to reduce pollution (Ebenstein, 2012). A one grade deterioration in water quality, as measured on the national water quality system discussed above, is found to be associated with an almost $10 \%$ increase in the incidence of cancer. Further, the compliance costs for improving industrial wastewater quality appears low when compared with statistical value of life estimates for China, implying a compelling economic case for mitigation. This is particularly so as the study focuses on only one type of illness associated with poor quality water and is therefore likely to understate the full health benefits of reducing pollution.

The Chinese government has invested heavily over a number of years to increase access to improved drinking water, which has helped to boost public health (Zhang, 2012). These investments have focussed on expanding the mains network, in order to increase access to piped water, as well as treatment facilities, to improve water quality. In urban areas access to piped water has risen rapidly and is now approaching universal levels. However, water quality remains a concern with government officials stating that $17 \%$ of water supplies failed to meet official standards, possibly because water is so heavily polluted that standard water treatment facilities are less than fully effective (Liu, 2012). Though access to piped water in rural areas has also risen rapidly, still less than half of the population is covered. A further $40 \%$ of the rural population have access to water from an "improved source" such as a well but the extent to which these sources provide protection from pollution is unclear (WHO-UNICEF, 2012). A sizeable share of the population likely remains exposed to water pollution related health threats either through direct ingestion or through food chain contamination. The latter can occur directly, through the consumption of fish or other aquatic life, or through the use of polluted water to irrigate crops (Zhang et al., 2010a).

Though aggregate estimates of the costs of environmental degradation are useful in underscoring the justification for policy intervention they do not, in general, take account of distributional concerns. Health problems associated with pollution can have disproportionately large impacts on the poor, who may suffer greater exposure to pollution and have fewer options to relocate, working against government objectives to promote a harmonious society. In the case of water pollution, this is corroborated by Ebenstein (2012) who shows the association between pollution and health problems is higher in areas with lower access to tap water. Although public spending on health care and health insurance coverage have improved considerably in China, significant out-of-pocket expenses for serious illness remain a problem (OECD, 2010a). Consequently the poor may also endure a greater financial burden from adverse health caused by environmental problems. In addition, farmers and the poor stand to lose the most from environmental 
pressures such as climate change, which could lead to more volatile weather and hence less reliable agriculture production patterns and farm incomes, and greater volatility in food prices.

In a number of ways, environmental developments in China have global repercussions. Many types of harmful air pollutants travel across national boundaries or continents, depending on their size and residence time, potentially affecting local air quality far from their source (OECD, 2008). CO, ozone, mercury and particulate matter can travel well beyond China's borders. Indeed, empirical modelling by Saikawa et al. (2009) indicates that Chinese emissions of $\mathrm{SO}_{2}$ and black and organic carbon have had serious adverse health impacts abroad, especially in neighbouring regions. They report that under a business-as-usual baseline such adverse impacts would rise substantially but also that significant benefits would accrue, both to China and other countries, from efforts to reduce air pollution over the medium term.

Policies that impact the future path of Chinese GHG emissions will have a major bearing on the outcome of international efforts to avoid the most serious adverse consequences of climate change. Modelling presented in the OECD Environment Outlook (OECD, 2012a) shows how collective commitments countries have given to controlling their own emissions can be compatible with the internationally agreed objective of limiting global GHG concentrations to 450 parts per million of $\mathrm{CO}_{2}$ equivalent by the end of the century. For China, in the short run this includes reducing $\mathrm{CO}_{2}$ intensity, increasing forest areas and boosting reliance on renewable energy. As China has overtaken the United States as largest emitter and is on one of the fastest near-term emission growth trajectories, under a leastcost scenario the absolute reduction in GHG emissions to be achieved by China relative to a business-asusual baseline is larger than for any other single country. Deviations from this abatement scenario would therefore set back global progress in addressing climate change.

Given the severity of pollution in China, efforts to tackle environmental challenges are likely to deliver large co-benefits. As noted, several types of pollution originate from the same sources and in major Chinese cities, concentrations of the key air pollutants such as $\mathrm{SO}_{2}, \mathrm{NOx}$ and PM tend to be strongly correlated. Interactions between some pollutants mean that lowering primary air pollutants will also help reduce secondary pollutants. Efforts to promote cleaner energy and improve energy efficiency will reduce various types of pollution, lower compliance costs and promote better health, thereby lowering health care costs. Several co-benefits can also arise from efforts to make cities more environmentally friendly, including expanded public transport, which can reduce energy consumption and improve mobility, especially amongst poorer households.

\section{Addressing environmental priorities in the 12th FYP will require a broad policy response}

Improving environmental outcomes is one of the central aims of government policy, as underscored by the 12th FYP which includes a number of environmental targets to build on successes in the 11th FYP (Box 1). Targets to further reduce $\mathrm{SO}_{2}$ and $\mathrm{COD}$ and, for the first time, for NOx and ammonia nitrogen, have been included. As a signatory to a number of key international environmental agreements, including the UNFCCC and Kyoto Protocol, China abides by the principle of "common but differentiated responsibilities" and has signalled its appreciation of the importance of aligning domestic climate change policies with international efforts. In 2009 the government announced a commitment to reduce the carbon intensity of production by between $40 \%$ and $45 \%$ in 2020 relative to 2005 and as a stepping stone to meeting this goal the 12th FYP includes, for the first time, a target to reduce $\mathrm{CO}_{2}$ intensity by $17 \%$. The Plan also foresees further significant improvements in energy and water efficiency, which are intended to yield indirect environmental gains, as well as increases in forest coverage. 


\section{Box 1. China's Five Year Plans for Environmental Protection}

The medium-term priorities and principal objectives of Chinese public policy are laid out in five year plans (FYPs). The national plan, which provides the broad direction across the full range of policy areas and sets out key performance targets, including an objective for economic growth, is formally prepared by the State Council with the National Development and Reform Commission playing a lead role in co-ordination and drafting, in conjunction with ministries and other agencies. Once the national plan has been approved by the National People's Congress, sectorspecific plans, including for the environment, are devised by line ministries. Policy planning is conducted in a top-down manner with the national plan used as the basis for establishing sub-national plans with their own specific policies and targets in a cascading manner, first at the provincial level and then down to more local levels of government. As emphasised in the current environmental plan, local governments ultimately have primary responsibility for effective policy implementation.

Efforts to address environmental challenges have gathered momentum over time and this has been reflected in recent FYPs. In the 9th FYP (1996-2000), the government for the first time articulated numerical targets for controlling some types of air and water pollution, as well as other environmental objectives (Chang and Wang, 2010). More stringent $\mathrm{SO}_{2}$ and $\mathrm{COD}$ reduction targets were set out in the 10th FYP but were not achieved. In contrast marked progress was made during the 11th FYP which again set targets for reducing key pollutants as well as improving air and water quality and increasing energy and water efficiency (Table 2).

Table 2. Summary of main environment related targets and outcomes for the 11th and 12th FYPs

\begin{tabular}{|c|c|c|c|}
\hline \multirow[b]{3}{*}{ Pollution emissions } & \multicolumn{2}{|c|}{ 11th FYP } & \multirow{2}{*}{$\begin{array}{l}\text { 12th FYP } \\
\text { Targets }\end{array}$} \\
\hline & Targets & Outcomes & \\
\hline & & & \\
\hline Sulphur dioxide & $\downarrow 10 \%$ & $\downarrow 14.3 \%$ & $\downarrow 8 \% *$ \\
\hline Chemical oxygen demand & $\downarrow 10 \%$ & $\downarrow 12.5 \%$ & $\downarrow 8 \% *$ \\
\hline Nitrous oxides & No target & NA & $\downarrow 10 \%$ * \\
\hline Ammonia nitrogen & No target & NA & $\downarrow 10 \% *$ \\
\hline $\mathrm{CO}_{2}$ emissions per unit of GDP (\%) & No target & NA & $\downarrow 17 \% *$ \\
\hline \multicolumn{4}{|l|}{ Air and water quality } \\
\hline $\begin{array}{l}\text { Proportion of cities meeting Grade II air } \\
\text { quality standard }\end{array}$ & $\uparrow 5.6 \%$ & $\uparrow 4.1 \%$ & $\uparrow 5 \%$ \\
\hline $\begin{array}{l}\text { Proportion of water system meeting Grade III } \\
\text { standard }\end{array}$ & $\uparrow 2 \%$ & $\uparrow 18.9 \%$ & $\uparrow 8 \%$ \\
\hline $\begin{array}{l}\text { Proportion of water system worse than } \\
\text { Grade V standard }\end{array}$ & $\downarrow 4.1 \%$ & $\downarrow 10.6 \%$ & $\downarrow 2.7 \%$ \\
\hline \multicolumn{4}{|l|}{ Energy production and resource use } \\
\hline $\begin{array}{l}\text { Share of non-fossil fuel usage in primary } \\
\text { energy consumption }\end{array}$ & No target & NA & $\begin{array}{l}\uparrow .1 \text { percentage } \\
\text { points }^{*}\end{array}$ \\
\hline Energy consumption per unit of GDP & $\downarrow 20 \%$ & $\downarrow 19.1 \%$ & $\downarrow 16 \% *$ \\
\hline $\begin{array}{l}\text { Water consumption per unit of industrial } \\
\text { value-added }\end{array}$ & $\downarrow 30 \%$ & $\downarrow 36.7 \%$ & $\downarrow 30 \% *$ \\
\hline \multicolumn{4}{|l|}{ Forests and farmland } \\
\hline Forest coverage rate & No target & NA & $\uparrow 1.3 \% *$ \\
\hline Forest stock & No target & NA & $\uparrow 4.4 \%{ }^{*}$ \\
\hline
\end{tabular}

Notes: Urban air quality refers to the number of days in which urban air quality of key cities is superior to Grade II for more than 292 days of the year. An asterisk denotes binding rather than notional targets for the 12th FYP.

Source: Chang and Wang (2010), Guerin and Wang (2012), CCICED (2011), NBS-MEP (2011) and State Council (2012).

In the 12th FYP (2011-15), targets have been set to further reduce $\mathrm{SO}_{2}$ and COD emissions as well as to improve ambient air quality in cities and surface water quality across lakes and rivers. For the first time an official target to reduce NOx emissions and ammonia nitrogen discharge, both by $10 \%$, as well as a target to reduce $\mathrm{CO}_{2}$ intensity, by $17 \%$, have been included. Reflecting the government's concerns for regional equity and disparities in development and industrial and energy structures, carbon intensity targets vary across provinces, ranging from a $10 \%$ reduction for the poorer western provinces of Qinghai and Tibet up to a $19.5 \%$ reduction for the wealthier coastal province of Guangdong. Each of these targets are prescribed as "binding" rather than "notional", underscoring the importance the government attaches to ensuring they are met. A numerical target to reduce emissions of heavy metal pollutants in some regions, and to cap discharges elsewhere, has also been set. In addition, the Plan specifies strategies for monitoring and controlling other pollutants, including persistent organic pollutants and VOCs, though it does not 
prescribe targets. The other main environmental targets relate to increasing the forest stock and coverage rate as well as improvements in resource efficiency and lessening the reliance on fossil fuels. Following a fall in energy intensity during the 11th FYP, a further reduction of $16 \%$ has been enshrined in the 12th FYP while water intensity, measured as water consumed per unit of industrial value-added, is set to decline by $30 \%$. An interim assessment of progress in implementing these targets and other Plan objectives will be made at the end of 2013 before a full assessment at the end of 2015.

Aside from improving energy efficiency the government plans to diversify energy sources and reduce reliance on coal by continuing to raise the share of non-fossil fuels in primary energy production by just over 3 percentage points, to around $11 \%$ by 2015 . Beyond the 12th FYP this share is targeted to increase further to $15 \%$ by 2020 (Information Office of the State Council, 2012). The planned expansion in nuclear capacity is very large, with the number of reactors set to rise from the current 15 to a total of 40 . However, following the 2011 nuclear disaster in Fukushima the Chinese government promptly halted construction of new reactors and ordered a safety review of existing facilities. Construction on existing projects has recently resumed but the government is yet to deliver an expected revised medium-term plan which could either confirm the existing target or articulate an alternative. Changing the energy mix towards cleaner sources will help meet $\mathrm{CO}_{2}$ emissions and other environmental targets although even if the intended rebalancing is achieved consumption of coal and other fossil-fuels will continue to rise strongly.

A broad suite of measures have been introduced to encourage renewable energy investment with the Renewable Energy Law, which came into effect in 2006 before being amended in 2009, and associated regulations providing the legislative umbrella. Critically, it requires grid companies to connect all renewable energy projects and purchase the supplied electricity. This was complemented by the introduction of a feed-in tariff (FIT) for wind power in 2009, which varies across provinces depending on local weather patterns, and for photovoltaic energy in 2011. These incentives have been financed by an electricity surcharge that applies to all end-users. Such measures have been complemented by other incentives under the auspices of special schemes including the "Golden Sun" initiative, which provides direct subsidies to investment in photovoltaic projects. The renewable energy and other environmental sectors have also benefited from considerable funding channelled through the Clean Development Mechanism. China accounts for $71 \%$ of all primary market Certified Emission Reduction permits issued between 2005 and 2011 (World Bank, 2012). However, with the decline in European carbon prices this source of funding has contracted. Furthermore, in rural areas the government promotes the use of cleaner indoor fuels for cooking. In 2011, subsidies for biogas purchases were raised to between CNY 1300 and 2000 per household depending on the location and the government has spent CNY 4.3 billion improving biogas distribution systems (MEP, 2012).

Aside from furthering environmental goals, diversifying the energy mix supports energy security objectives. Despite a large coal endowment, China recently became a net importer of coal. It then quickly overtook Japan as the world's largest importer in 2011, accounting for around $18 \%$ of the global total (IEA, 2012b). The largest coal-producing regions in China are located in the north and western provinces whereas as demand is greatest in the eastern provinces. Given poor electricity network interconnectivity and the strain placed on the domestic rail network from transporting coal, foreign sourced seaborne coal is often more economic. China has been a net importer of oil for many years and despite the continued expansion in domestic production dependence on foreign sources has risen, reaching over $55 \%$ in the first half of 2012. In this context, the government has pursued the development of large domestic reserves of other fossil-fuel resources, notably unconventional natural gas, including shale gas (IEA, 2012c). It has also set up a strategic petroleum reserve, which is intended to ease short-term oil supply constraints and smooth price fluctuations (IEA, 2012d). This reserve is being developed in three phases, the first of which saw the construction of over 100 million barrels of storage capacity by 2008 with a second phase expected to add a further 200 million barrels of capacity by 2013 . 
Governments at all levels, as well as the private sector, have invested vast sums in key environmental related infrastructure to reduce immediate sources of pollution, notably in water and waste treatment facilities and public transport. Investment in pollution treatment alone amounted to $1.7 \%$ of GDP in 2010, up from 1\% of GDP in 2000 (NBS-MEP, 2011).This has led to a more than doubling of the wastewater treatment rate in urban areas, which reached over $80 \%$ by 2010 . A further expansion of infrastructure for the collection and treatment of household sewerage, including in towns and villages, is envisaged. At the same time efforts will be stepped up to reduce environmental risks from accidents, including spillage of toxic material, and strengthen solid waste collection and promote the "circular economy", a Chinese term which refers to reducing waste and reusing and recycling materials. Farmers will also be encouraged to make better use of low-impact techniques, including manure recycling, as well as to rationalise the use of fertilisers and pesticides. For larger livestock farms the 12th FYP envisages a rapid expansion in excrement treatment facilities. High importance is attached to reducing pollution in heavily degraded areas such as the Chaochi and Dianchi watersheds and the Huaihe River basin. In these areas it appears that local authorities will be expected to apply particularly stringent standards to emissions sources or possibly restrict the scope of polluting activities altogether.

Success in reducing emissions of some pollutants, especially from industrial sources, has been achieved principally through end-of-pipe technological solutions supported by large expenditures on environmental infrastructure. This includes a strong ramp-up of desulphurisation technology which had been installed in $95 \%$ of thermal power generators by 2011, a large increase from even a few years earlier (MEP, 2012). Swift progress was aided by a policy to pay power generators higher electricity prices where desulphurisation technology is installed. The uptake of denitrification technologies has lagged in comparison and less than 5\% of NOx emissions were removed from industrial sources in 2010 (MEP, 2011a). However, in 2011 the government also began offering subsidies to power generators to install denitrification equipment which is likely to accelerate progress in this area. In addition, new standards for thermal power generation were introduced in early 2012, in line with EU and United States ones, with similar caps for emissions of $\mathrm{NOx}, \mathrm{PM}, \mathrm{SO}_{2}$ and mercury. All new large thermal power generators are now expected to install denitrification as well as desulphurisation technology and similar standards are being applied to heavy industry.

Improvements in energy efficiency have been targeted through several measures, many of which have come under the "Ten Key Energy Conservation" scheme through which financial support was disbursed to encourage firms to deploy newer, more efficient equipment. The "Top 1000 Enterprises" programme involved energy audits and the promotion of energy conservation plans in around a third of the nation's highest energy consuming enterprises. Under the 11th FYP, many small, less efficient thermal power generators were shut down, as was a sizeable chunk of outdated industrial production capacity, especially in highly polluting and energy-intensive sectors (Information Office of the State Council, 2011). Total closures amounted to over 76 million KWs of generation capacity as well as significant capacity in the cement, coke, glass, iron and paper sectors. Further progress in these areas was made in 2011 (NDRC, 2012). Large-scale retrofitting for residential and commercial buildings has also made a major contribution to energy conservation. A focus has been retrofitting central heating facilities, to increase household metering, install technology allowing local temperature regulation and improve heat transfer efficiency. During the 11th FYP retrofitting of this kind was undertaken in a total of 190 million square metres of residential floor space (Bao et al., 2012).

Moves to tackle pollution and promote energy efficiency and renewable energy have led to an expansion in environmental-related sectors of the economy. During the second half of the 2000s the number of energy conservation service companies ballooned more than ten-fold to over 800 with a similar rise in employment (Information Office of the State Council, 2011). The expansion of renewable energy capacity has also occurred in tandem with China's rise as a leading manufacturer and exporter of renewable energy equipment. In 2010, China accounted for over half of global solar module production, up from $39 \%$ just a year earlier (IEA, 2011a). This expansion has been accompanied by sharp falls in module 
prices which have supported the expansion of renewable energy around the world. Further efforts to strengthen environmental policy will continue to create new economic and employment opportunities in these areas. In addition, many of the strategic sectors that the government is actively promoting are intended to have strong environmental linkages, notably energy conservation and environmental protection, new energy sources (including renewable energy) and alternative energy vehicles.

Further closures of outdated and inefficient power generation and industrial capacity are envisaged in the 12th FYP, which also expands some 11th FYP initiatives, including the "Top 1000 Enterprise" programme, which has become the "Top 10000 Enterprise" scheme. While there are likely to be further gains from such measures the scope has undoubtedly diminished and administrative costs could well rise substantially given the larger number of smaller firms involved. The scope for large improvements in thermal power generation and industrial energy efficiency has also narrowed. As a result of policy interventions and investments in more modern facilities the share of larger and more efficient thermal generators rose from less than half in 2005 to over $70 \%$ by 2010 and over the same period the proportion of large-scale industrial furnaces more than doubled (National Energy Conservation Center, 2011). In some areas of the country wastewater treatment rates have risen to very high levels and the application of desulphurisation technology is reaching saturation point. Although there may be scope for expanding use in industrial boilers, the very large number of these facilities makes verification difficult while it may be technically or financially infeasible for smaller scale units (Wang et al., 2012a). Moreover, the cost of relying on command-and-control approaches was underscored towards the end of the 11th FYP when the achievement of the Plan targets was at risk (Zhang, 2010). In several provinces local governments implemented rolling blackouts for thousands of factories, shutting off power supplies for five days after nine days of continuous operation. In addition to disrupting production, power shortages impair productivity and increase uncertainty and are estimated to have raised firm operating costs by up to $20 \%$ in China during past episodes (Fisher-Vanden et al., 2012).

While significant, in some respects the environmental achievements to date represent the "lowhanging fruit", amenable to command-and-control measures and infrastructure upgrading. This is particularly so regarding reductions in $\mathrm{SO}_{2}$ and $\mathrm{COD}$ from point sources, including power generation and heavy industry, that have been accomplished primarily through end-of-pipe solutions. Going forward more emphasis ought to be placed on the use of a broader range of tools, including well-implemented marketbased measures, to tackle a wider range of challenges. Such changes will form part of the broader reform effort needed to rebalance the structure of the Chinese economy, including moving towards more consumption and services-oriented growth. Indeed the greatest scope for increasing employment in less polluting and energy-intensive industries is likely to lie in the expansion of labour-intensive service sectors, which are the predominant employers in mature economies and will account for an increasing share of the Chinese economy over the medium term. 


\section{Market-oriented reforms will help improve resource efficiency}

\section{Energy policies have improved but further changes are required}

Ensuring that energy prices faced by end-users reflect underlying costs is key to achieving energy efficiency and environmental goals (OECD, 2012b). This is especially so in China given the heavy reliance on coal as the primary source of energy. As in many other countries, energy pricing policies in China have been guided by a range of economic, social, strategic and, more recently, environmental objectives. Historically, prices of many energy products have been heavily regulated to ensure price stability and to pin down costs faced by end-users. However, gradually price liberalisation has promoted convergence between domestic and international prices. In the case of coal, progress was made by the mid-2000s, when the government eased price guidance and allowed domestic coal prices to move up sharply in line with international prices (IEA, 2009). However, coal suppliers are still required to sell some coal to power generators below market cost. Price regulation of other energy sources endures, sheltering consumers from cost changes or redistributing costs across types of consumers.

Regulated domestic oil product prices in China have been set with reference to international crude oil prices for over a decade. End-user prices and the extent of price pass-through have also been determined taking into account the profit margins of domestic state-owned oil refineries, which dominate the Chinese market. In 2007 and early 2008 the pricing mechanism came under pressure as international oil prices surged. The government's initial response was to hold back increases in retail prices, resulting in rising subsidies and mounting financial losses for refineries. As international crude prices rose above $\$ 120$ per barrel in mid-2008 the government changed track, lifting regulated prices sharply. This raised refinery profit margins and stemmed financial losses (Figure 8). At the same time it announced a new pricing mechanism that has been in operation since the beginning of 2009. Under these arrangements, so long as international prices remain below $\$ 130$ per barrel, domestic prices are adjusted when the average of three international crude spot prices (Brent, Cinta and Dubai) moves by $4 \%$ or more over a 22 -day period. Since the implementation of this policy, the unit difference between oil and gasoline prices has been very stable, implying strong pass-through. However, it is unclear how the government would respond were international oil prices to rise above $\$ 130$ per barrel.

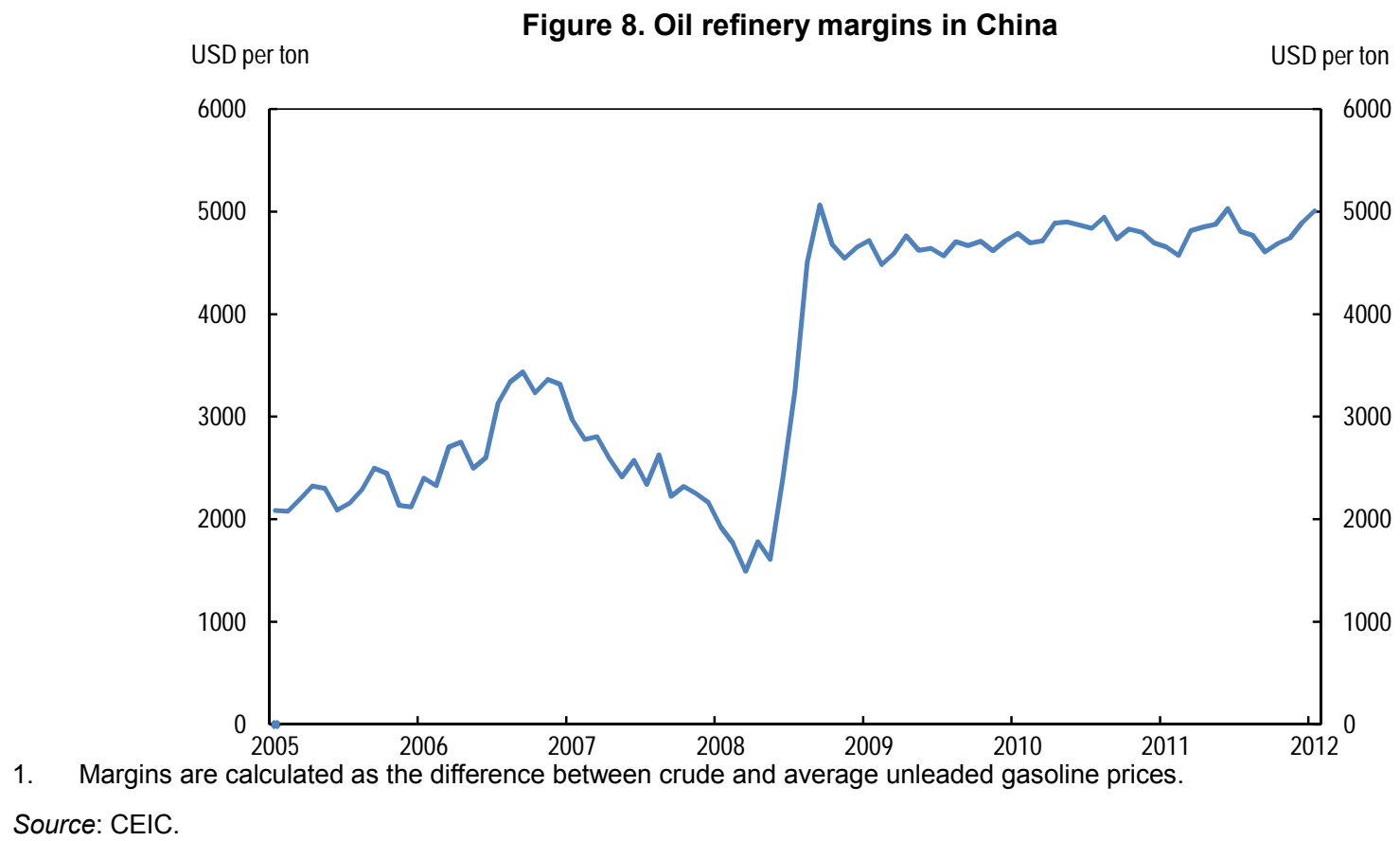


Complementing these changes, in 2009 a fuel excise tax was introduced, at a rate of CNY 1 per litre for gasoline and CNY 0.8 per litre for diesel (Wang, 2011). However, these changes were partially offset by the removal of other taxes. By international standards Chinese gasoline prices remain relatively low, even though they are higher than in some OECD countries, notably the United States. Following recent price reforms, tax-exclusive prices in China are now close to the average for OECD countries, hence differences in final prices primarily reflect lower taxes - at less than $30 \%$ versus $50 \%$ of the final price (Figure 9). Thus, there is considerable scope to increase excise rates on gasoline and other petroleum products in order to support a number of policy objectives, though identifying the optimal level of taxation raises several issues. An ideal (Pigouvian) tax would reflect the full suite of externalities. A further consideration is that petroleum-related taxes are often less distorting and more economically efficient than alternatives as the price elasticity of demand tends to be low (Lin and Zeng, 2012a). Lin and Zeng (2012b) estimate that a Pigouvian tax could be in the order of CNY 2.8 per litre, close to CNY 1 per litre more than the current total tax. However, an even higher rate could be justified given the low estimated price elasticity of demand. Thus at a minimum the current excise rate should be doubled.

Figure 9. Tax share of retail diesel and gasoline prices

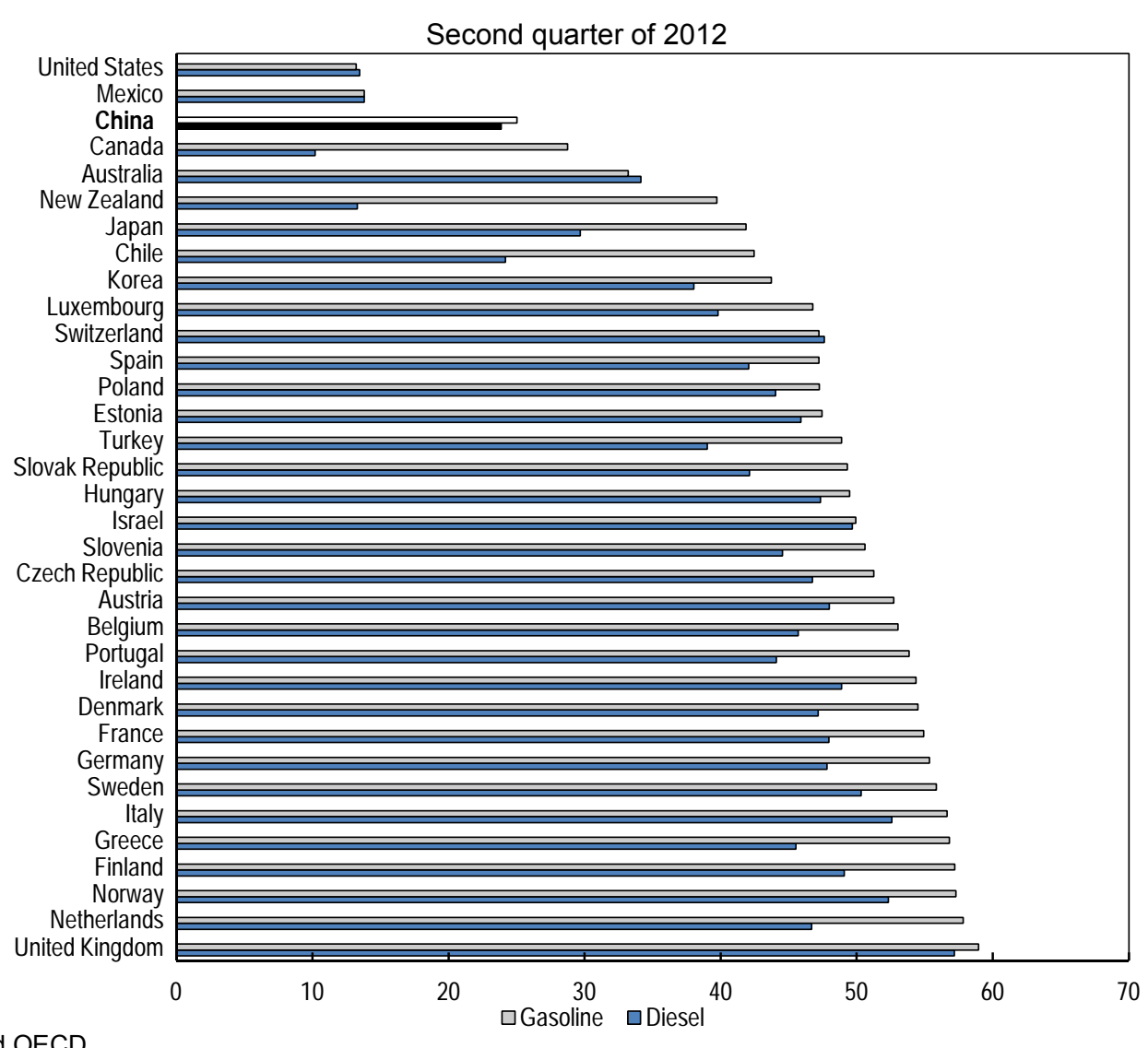

Source: IEA and OECD.

In contrast to the oil sector, little progress has been made in reforming natural gas pricing. The government currently sets prices paid to producers based on production costs and adjusted according to prices for alternative types of energy. Prices also depend on whether the gas is destined for household or industrial users. This has led to large variations in prices nationally, with consumers in areas that can access cheaper domestically-produced gas enjoying lower prices, to the detriment of local producers, while consumers relying on imported gas face higher, internationally determined prices. The government has launched pilot schemes to experiment with more market-oriented pricing in the southern provinces of Guangdong and Guangxi, which already rely heavily on imported gas. Under these schemes city gate 
prices will be based on a market-determined reference rate which no longer depends on the end-user or gas source, thereby ensuring that all consumers face a price determined by prevailing supply and demand. Once the government is satisfied that these arrangements are workable it should unroll them nation-wide.

Likewise, little progress has been made in reforming electricity since the early 2000s, when a large vertically integrated state-owned monopoly was broken up in an attempt to move towards a more marketoriented set-up (Ma, 2011). Prices received by generators and faced by end-users remain regulated and although electricity generation is separated, transmission and distribution remain bundled together. Most assets are still directly or indirectly controlled by the government. While private investment in power generation has been allowed for many years, and has expanded, the market is dominated by a small number of state-owned operators and local government ventures. Moreover, as generators are required to sell power directly to the grid at a government-determined price there is currently little effective competition in this segment. The distribution and transmission sector is highly concentrated with only two enormous state-owned operators serving almost the entire market, either directly or through their subsidiaries.

Prices paid by end-users and received by generators are supposed to be set by the State Council through the NDRC. In theory, a cost-based approach is applied to determine on-grid prices paid to coalpowered generators with the aim of ensuring a rate of return that encourages sufficient investment and growth in capacity (Liu and Zhang, 2012). The price is set in tandem with a quota for the amount of power each generator must supply to the grid. In practice, however, prices received by generators have not kept pace with rising coal prices. This has led to a financial squeeze on power generators and forced them to offset losses incurred from power generation by expanding activity in profitable non-core businesses including component manufacturing. Electricity prices to end-users also often deviate from the nationallydetermined benchmark, with provincial and local governments at times employing preferential pricing to support industrial objectives (Chen, 2011). Prices also vary geographically depending on the level of affluence, with lower prices offered in poorer regions. Electricity prices are hence used as both a redistributive tool as well as an instrument for industrial policy. However, as environmental protection sometimes lags in the poorer parts of the country, luring businesses to these areas through cheaper energy is likely to be particularly environmentally harmful.

On average, electricity prices faced by industrial users in China are not unusual compared with many OECD countries but household prices are much lower (Figure 10). In most OECD countries prices for industrial users are lower than for households but in China the situation is reversed. Households, select businesses, and consumers in poorer regions are the main beneficiaries of the current approach to pricing in China. Increasing price differentiation across households is in fact one of the aims of reforms to pricing structures introduced in 2012. Under this new approach the unit price rises when consumption exceeds a threshold so that higher-consuming households pay more (the precise formula applied varies across provinces). While representing an improvement, prices are still comparatively low. Arrangements in the electricity sector have ensured a massive expansion in capacity but limiting the pass-through of higher generation costs to end-users hinders efforts to improve energy efficiency and, given the ongoing reliance on coal as the primary source of energy, reduce pollution.

Reforming electricity prices can promote environmental objectives and strengthen competition, which would improve efficiency and ultimately benefit downstream users. There is evidence that under the current pricing arrangements less efficient generators are paid a higher price (Beirne et al., 2012). This reduces the incentive for electricity producers to minimise costs, penalises more efficient generators and, ultimately, firms and households. As a first step forward wholesale prices need to better reflect costs to restore the financial health of generators and ensure adequate investment in capacity. At the same time the government should fully liberalise the market for thermal coal. It should then experiment with separating transmission from distribution in some segments. If this proves successful it should be generalised with a view to creating a market-based system for electricity pricing. 
On the basis of a price-gap method, which measures the difference between final consumer prices and the cost of supply, it is estimated that in 2010 fossil-fuel related subsidies amounted to just under $0.4 \%$ of GDP in China (IEA, 2011b). This is low compared to some other large emerging economies including India, where subsidies amounted to around $1.4 \%$ of GDP, and Indonesia and Russia, where they were more than $2 \%$ of GDP. The largest component of the subsidy relates to electricity, with smaller amounts for oil and coal. The value of Chinese fossil-fuel subsidies has fallen considerably in a short period reflecting the important reforms undertaken to allow a fuller pass-through of changes in raw energy prices. Nevertheless, enduring subsidies of this type, which are economically and environmentally damaging and work against several government policy objectives, underscores that reform in this area is incomplete and changes that lead to the elimination of all fossil-fuel subsidies and allow full pass-through of energy prices should be prioritised. Aside from improving energy efficiency, eliminating such subsidies and recycling the fiscal windfall has been shown to produce significant co-benefits in China by boosting economic output and employment as well as reducing $\mathrm{CO}_{2}$ and $\mathrm{SO}_{2}$ emissions (Lin and Jiang, 2011).

Figure 10. International household and industrial electricity prices

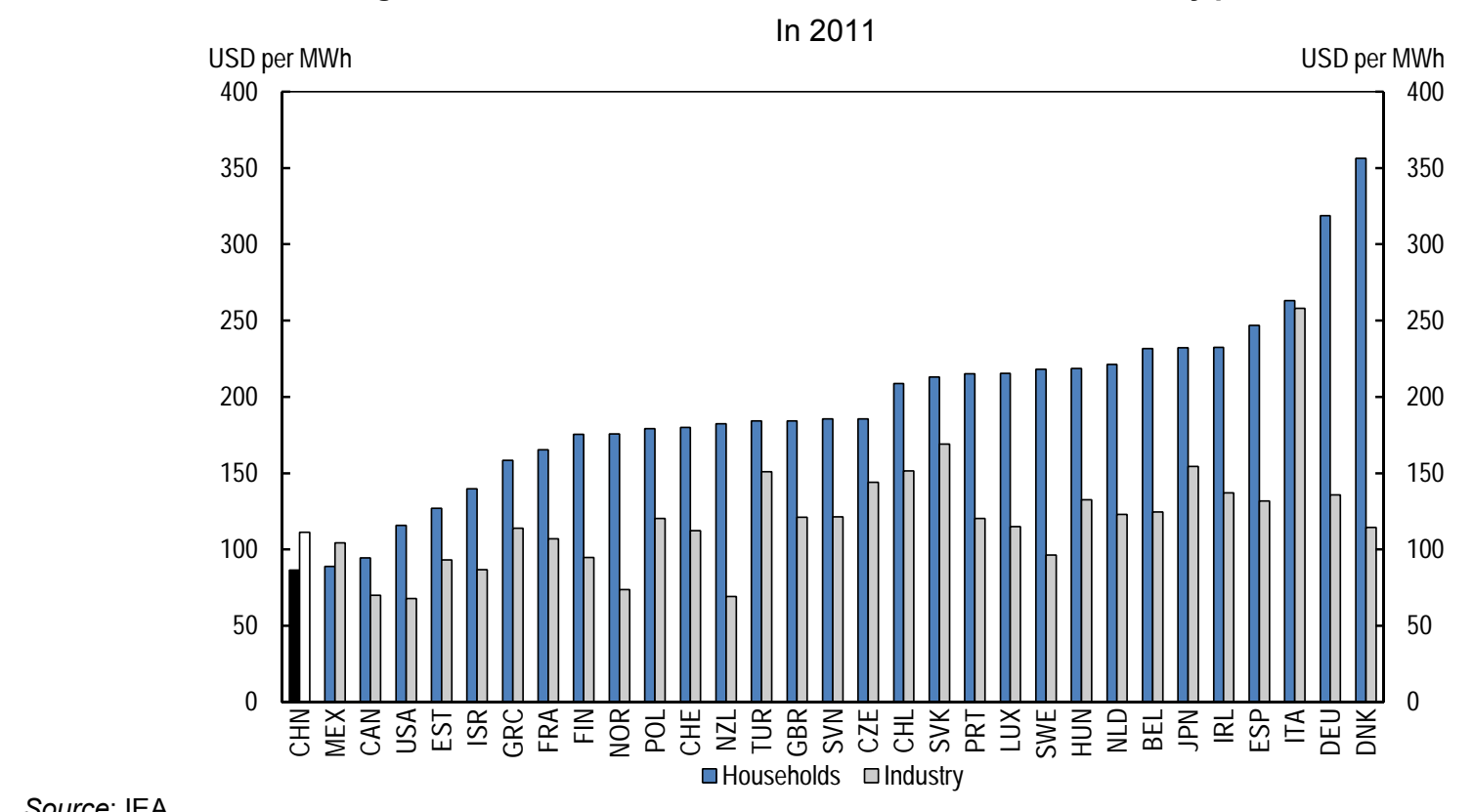

Source: IEA

\section{Reforms to improve water conservation}

Just as better pricing of energy can help improve energy efficiency and reduce energy-related pollution, appropriate water pricing can help ensure water is used more efficiently and lower water pollution. It can also help ensure adequate funding and incentives for essential water infrastructure. As noted above, water efficiency in China has improved but overall water consumption across all sectors except agriculture has risen over the past decade and water pricing policies have evolved with the aim of discouraging waste and recouping water supply costs (Zhong and Mol, 2010; Li et al., 2011). Water charges are determined at the local level and levied either by water supply companies that deliver piped water to households and industry or by local water resource bureaus for direct abstractions from rivers and lakes or groundwater reserves. A two-part tariff often applies for water obtained through either channel, whereby unit prices increase beyond a threshold level of consumption or abstraction. Water companies often bundle together water supply, water resource and wastewater treatment components into a single fee. According to national guidelines the wastewater component is supposed to be set on a full cost recovery basis. In contrast, national guidelines for abstraction fees are less clear but are notionally determined on the basis of local water scarcity and equity considerations, which in practice mean that many farmers face very low prices. 
Average household water prices in cities rose steadily through the $2000 \mathrm{~s}$, but remain low compared with OECD countries, averaging around $\$ 0.28$ per cubic meter in 2010 (Figure 11). Abstraction fees are often even lower and in many cities the national policy to recoup wastewater service costs has not been enforced. As with special arrangements with energy pricing, preferential water prices have also sometimes been offered by local government officials as an inducement to business. Weak institutional capacity, including inadequate staffing amongst local water authorities, may also contribute to a low collection rate for water fees. A further problem that needs to be addressed at the national level is the absence of clear abstraction targets and the lack of a regional focus in determining usage limits or prices; abstractions are determined locally but have consequences for users downstream. Though river basin management committees exist, they lack the authority to set terms for local water authorities and their task is also often hampered by a lack of reliable data on water use and resources. Water prices are low and should be raised further to promote more efficient use. This should be done in tandem with institutional reforms to strengthen the effectiveness of market incentives although by virtue of raising the opportunity cost of offering exemptions or forgoing fee collection, raising prices will in itself strengthen the incentive to ensure that all water users meet their financial obligations.

Figure 11. International household water prices

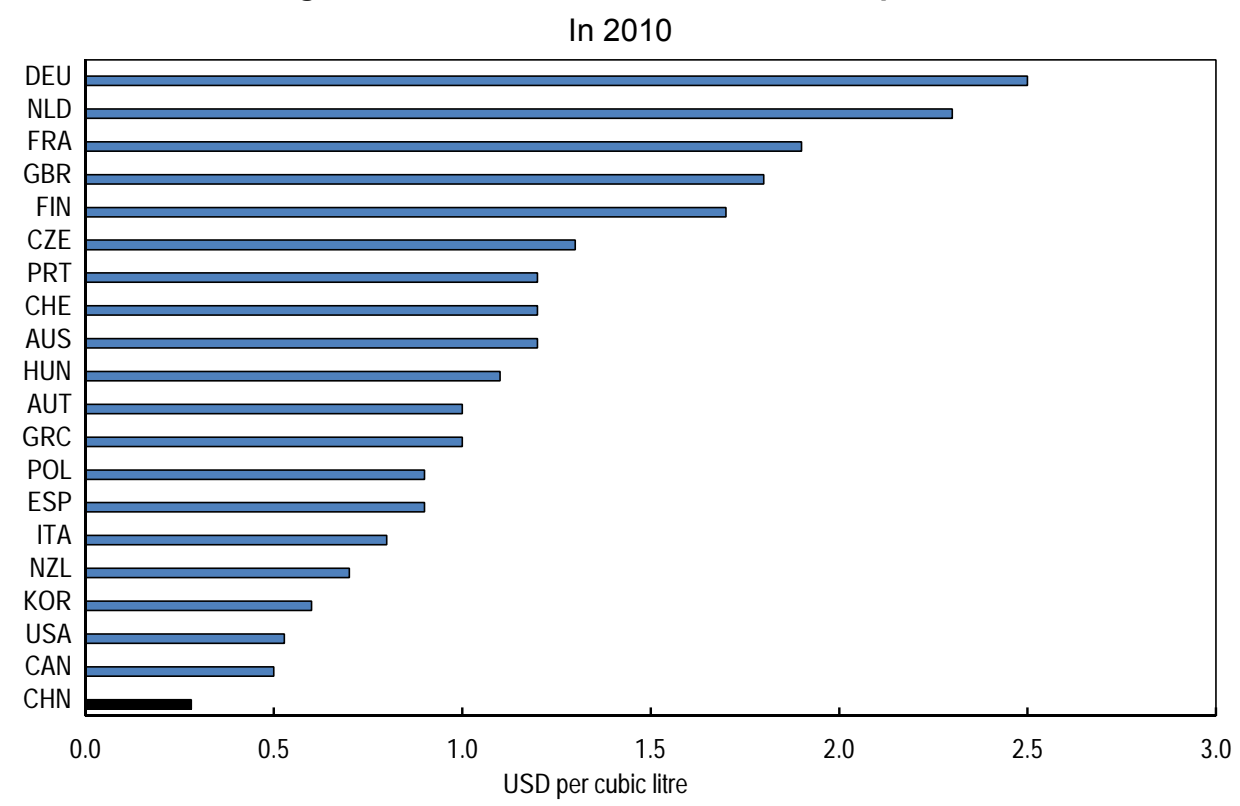

Note: England and Wales for the United Kingdom.

Source: OECD (2010b), EPA (2011) and MRW (2011).

Strengthening other incentives for better water management, including rewards for conservation, can also help improve water efficiency in the agricultural sector without necessarily affecting production levels. In response to water shortages farmers often resort to sinking tube wells, which facilitate access to groundwater, increasingly on a private rather than collective basis. The shift towards private ownership of these resources, which offer a finite supply of water, appears to promote more efficient as well as higher value added farming methods (Wang et al., 2009). At the same time, the proliferation of private tube wells has given rise to local water markets, with owners selling water to other users. In addition to providing an additional income stream for those farmers selling water, as well as an additional water supply source for buyers, it has helped promote efficiency, with those farmers who need to buy water using less of it to generate the same crop yields. To help promote water efficiency in rural areas the government has a longstanding policy of decentralising water management, which has led to the emergence of irrigation management contractors. However, an analysis of the impact of these contractors revealed that they only helped improve water efficiency when regulations allowed them to generate profits through water savings (Wang et al., 2009). 
As water and energy pricing arrangements are often motivated by equity considerations, reforms in this area can be politically challenging, as underscored by international experience (OECD, 2011b). It is therefore often necessary to offset any distributional consequences by recycling fiscal windfalls back to households. In China, such reforms need not hurt the poor and in some cases could support equity objectives. Although car ownership is rising strongly across all household groups, ownership rates remain much higher in more affluent groups. Increases in gasoline and diesel taxes may therefore have a much smaller impact on the poor and could be further offset through higher subsidies for public transport. Where the impact on the poor is likely to be larger, including electricity and water reforms, transfers through the tax and benefit system could be raised. For the poor, direct financial support could be delivered through increases in the minimum living allowance (MLA), the coverage of which has expanded rapidly in recent years (OECD, 2010a). Indeed, following recent reforms the level of the MLA, which is determined by local governments, is supposed to adjust frequently in response to changes in the cost of living and hence would be expected to rise in tandem with higher energy and water prices.

\section{Appropriate pricing of pollution and support for renewable energy should form the cornerstone of policy}

Pricing pollutants either through taxes or levies or by introducing an emissions trading scheme (ETS) that creates a market for the right to pollute, offers an economically attractive and increasingly popular approach to help meet policy objectives (OECD, 2011b). When faced with a pollution price, each polluter decides on their own optimal level of investment in costly abatement. This ensures that the marginal cost of abatement is equalised across polluters and the goal of pollution reduction is achieved at the lowest possible aggregate cost. In addition, pollution pricing provides an ongoing incentive to find cheaper methods of mitigation through innovation, thereby promoting dynamic efficiency. Finally, pollution taxes or trading schemes create opportunities to generate fiscal revenue, a double-dividend, which can be used to fund public expenditures or reduce other more distorting taxes.

Instruments for pricing carbon and other pollutants, notably $\mathrm{SO}_{2}$, are well established in a number of countries, having gained favour with several governments around the world who have adopted carbon pricing as the focus of their efforts to limit emissions and meet climate change obligations (Ranson and Stavins, 2012). One of the largest, longest running and most successful schemes is the $\mathrm{SO}_{2}$ cap-and-trade scheme in the United States, established in the 1990s to help address acid rain problems. This facilitated lower emissions at a much lower cost than using command-and-control approaches (Chan et al., 2012). The EU emissions trading scheme (EU-ETS), established in the mid-2000s, is by far the largest carbon pricing regime in operation, covering about half of all $\mathrm{CO}_{2}$ emissions from 30 countries. More recently, smaller carbon trading schemes have been established in New Zealand, Switzerland and Tokyo, and are set to start in California, Quebec and South Korea. In Australia, a carbon tax was introduced in 2012 and is to be converted into a trading scheme in 2015 .

\section{Market-based environmental policies have a long history in China}

China has a long history of pricing pollution, having first established a pollutant levy system in the 1980s that covered different types of air and water pollution as well as waste discharge and noise (Wang and Wheeler, 2005; Ge et al., 2011). Reflecting high emissions, the revenue generated is sizable compared with most of the OECD countries that have dedicated pollution and other environmental charges, levies and taxes (Figure 12). Most of the revenues from these levies are generated from industrial air and water pollution and are often allocated to local mitigation projects as well as other environment-related spending, including for better monitoring facilities. Initially the wastewater levy was based on discharge standards, with levies only applying to those discharges which failed to meet a minimum standard. However, it was later revised to apply to all discharges, with a higher rate for those below the standard. In contrast, a flat rate applies to air pollution emissions. Levy rates vary across the country with a base rate set by the central 
government supplemented by an additional levy determined by local governments. In determining total levy liabilities the concept of "pollution equivalents" for a variety of different air and water pollutants is applied (McElwee, 2011). Despite continued high pollution emissions the value of national revenues generated from pollution levies is modest, amounting to less than $0.1 \%$ of GDP in 2010 .

Figure 12. Environmental charges, levies and tax revenues

In 2010

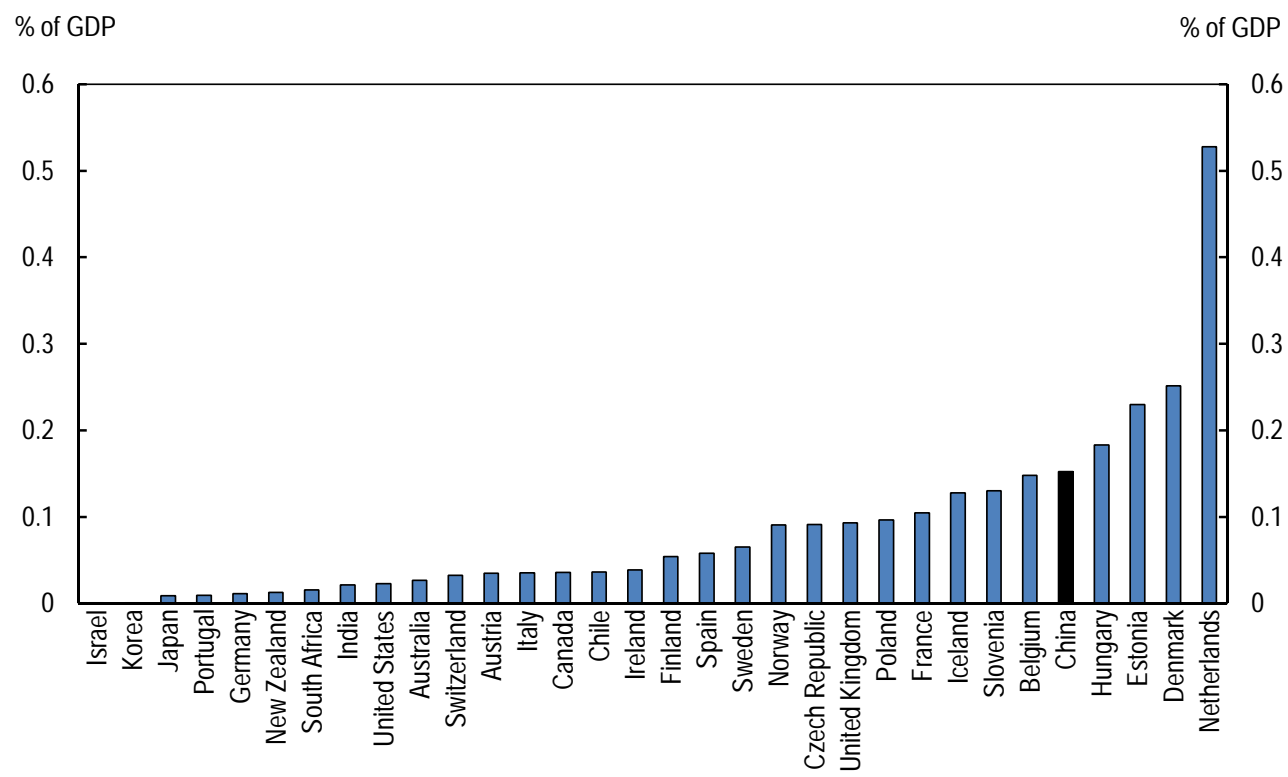

Note: Includes all revenues from environmental-related charges, levies and taxes except those relating to energy and motor vehicles. For Canada data refer to 2009.

Source: OECD.

Implementation problems, including a lack of monitoring and enforcement capacity, have plagued the pollution levy system. Although they are prescribed in legal instruments which stipulate penalties for noncompliance, in practice enforcement has been weak, with firms at times bargaining with local officials over their liabilities. A further problem has been that the levies have been too low to provide an incentive for firms to invest in mitigation efforts. During the 2000s, for example, only after a third increase did the $\mathrm{SO}_{2}$ levy exceed the average cost of pollution mitigation (Schreifels et al., 2012). The process of collecting pollution levies is also cumbersome, relying on a combination of self assessment and inspection by local environmental officials, and drains valuable resources from local agencies. In recent years revenues have fallen, reflecting the decline in total pollution discharges, which have narrowed the revenue base, but also declining levy rates. Although the $\mathrm{SO}_{2}$ levy rate rose until 2007 it has not changed since, implying a declining rate in real terms, while the average water pollution price has fallen in nominal terms since the mid-2000s (Figure 13). 
Figure 13. Average water pollution price

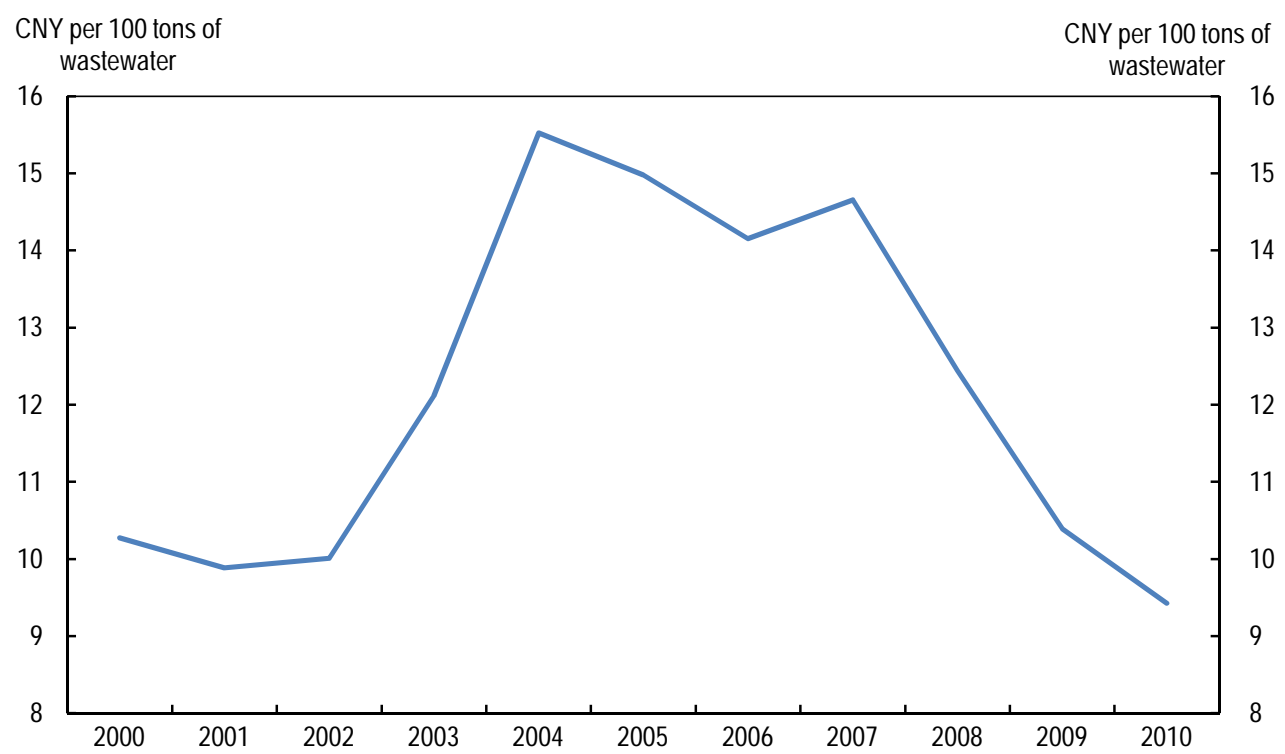

Note: The average water pollution price is calculated by dividing total wastewater levy revenues by the total volume of wastewater discharges.

Source: OECD and MEP.

Several experimental pollution emissions trading schemes, focussing on $\mathrm{SO}_{2}$ and to a lesser extent different types of water pollution, have also been undertaken in China (Jinnan et al., 2009); Chang and Wang, 2010). These have been promoted by the central government but have been implemented and administered by local governments and tended to be small in scale. The earliest pilot scheme that operated on a significant scale was established in 1991, focussed on $\mathrm{SO}_{2}$ emissions trading and initially involved 16 cities before expanding to a further six. Later, a small number of water pollution trading schemes were established in different localities and through the second half of the 2000s several new schemes covering air and water pollution arose across the country. However, in general, these schemes do not seem to have functioned well, often resembling a pollution charging system with only a notional possibility of pollution permits being traded freely.

Some schemes, particularly the early ones, appear to have operated with the narrow objective of facilitating the closure of old or outdated power generation or industrial capacity. Rather than allowing market forces to determine which firms had the right to pollute, governments required new operators to compensate those firms which were forced to exit the market. Where genuine trading of permits has occurred, in the absence of exchange platforms governments have played the role of intermediary and often had a major role in determining the price. A more fundamental problem is that firms have been reluctant to engage in voluntary market transactions owing to uncertainty. Part of the problem is that the schemes have lacked a clear legal basis. Though national environmental laws refer to the possibility of pollution emissions trading, the pilot schemes have been implemented on the basis of local regulations which provide less assurance. How these schemes interact with national policy measures and targets has also created uncertainty amongst firms. A further problem, particularly early on, was the absence of welldefined pollution targets. As a result firms have sometimes hoarded permits, leading to very low trading volumes and unclear price signals. These problems have been exacerbated by insufficient scale. As the schemes have typically been confined to a small geographic area such as a city or sub-jurisdiction, the number of participants in each scheme has been low, curtailing the potential size of the market. 


\section{Going forward more emphasis is needed on better implementation}

Despite the mixed experience with pollution charges and trading schemes thus far in China, the 12th FYP highlights market mechanisms as a tool to control pollution and carbon pricing is an element of the longer-term strategy to control GHG emissions and meet international climate change obligations (Information Office of the State Council, 2011). Against this backdrop, the government is establishing new pilot $\mathrm{CO}_{2}$ emissions trading schemes in seven sub-national jurisdictions: the provinces of Guangdong and Hubei and the cities of Beijing, Chongqing, Shanghai, Shenzhen and Tianjin. Some of these schemes will be operating at least on a preliminary basis in 2013 and the remainder by 2014. Initially, they will function separately but may be unified into a national trading scheme in the future. Trading will occur through local exchange facilities that were originally established to facilitate government asset sales and which could in the future be used to trade environmental instruments other than $\mathrm{CO}_{2}$ permits. In the first phase permits will be issued freely to enterprises covered by the schemes.

The emissions cap applying under each scheme will be set on the basis of local targets, as determined in the 12th FYP. As the Plan targets are based on emissions intensity, rather than absolute emissions, local governments will have to make estimates of the expected expansion in industrial output and then use these to impute the cap. Sector coverage varies across schemes but in general power generation and energy and emission intensive industrial sectors are to be included. In the largest jurisdiction with a pilot scheme, Guangdong, the first phase of the scheme will cover around 800 of the largest emitting enterprises in nine sectors: power generation, cement, ceramics, petrochemicals, steel, textiles, non-ferrous metals, plastics and paper. This will ensure that around $60 \%$ of industrial power consumption in the province will be covered.

The decision to establish separate pilot trading schemes was intended to provide the government with a rich source of information on how it might best set up a broader, national scheme. Some features of the pilots will, however, limit their usefulness as policy experiments. Disallowing trading across economically diverse jurisdictions limits the scope for trading and hence raises the aggregate cost of mitigation. In addition, in the case of Beijing, which imports most of its electricity from elsewhere in the country, indirect emissions from electricity consumption will be imputed on the basis of an assumed average level of emissions intensity. As no distinction is made for how electricity is generated the incentive to switch to cleaner power generation is reduced. The absence of trading between the schemes also makes it impossible for the government to identify problems it may encounter in moving towards a unified national system. If the pilot schemes are to be extended it may therefore be advantageous to merge some of them and monitor this transition.

A further difficulty in evaluating these pilots is that as they are intended to operate for a relatively short duration making it doubtful they can create the kind of market incentives necessary for firms to undertake costly mitigation investments with long-time horizons, such as building new renewable energy capacity. On a positive note, at least some of the schemes have the potential to operate on a sufficiently large scale to overcome many of the problems that have plagued earlier ETS experiments in China. In particular the scheme in Guangdong, which has a population exceeding 100 million and an economy similar in size to Turkey's, could create a trading market comparable in size to some national schemes.

An effective carbon pricing scheme, whether an ETS or carbon tax, must incorporate several key elements in order to function smoothly and meet its intended objectives of constraining emissions (Box 2). An institutional framework that is credible and provides firms with sufficient certainty is needed at the outset and several lessons can be learnt from domestic and international experience in this area. The difficulties faced by pollution trading schemes and levies within China underscore the importance of a clear and effective nationwide legal framework. The difficulty of providing clear and stable signals to firms and investors in a trading scheme is illustrated by carbon price volatility in the EU ETS. Determining 
an appropriate cap and avoiding an excess supply of permits is critical and hinges on an accurate assessment of current emissions. Though direct government intervention in the operation of an ETS is generally considered undesirable owing to the risk that it may give rise to inefficiencies, some interventions may be beneficial and indeed even necessary. If there is major uncertainty concerning the price of pollution the government can guide prices by establishing a ceiling (by issuing as many additional permits as required to limit price rises), or impose a price floor by reducing the number of permits released or entering the market to buy permits. The scope for such interventions could be built into the design of the scheme to avoid undue surprises. Ideally, carbon pricing should cover as many polluting sources as is practical. In practice this can present political difficulties and revenues generated from carbon pricing can be recycled to ease resistance. In the case of an ETS, auctioning permits not only provides revenues that can be used to help facilitate implementation but can also avoid disputes between different polluters that may arise from decisions about how free allocations are made.

\section{Box 2. Key features of effective carbon emissions pricing}

Carbon pricing can be achieved either through a carbon tax or an emissions trading scheme (ETS) where the latter represents a market for the right to pollute, as determined by the ownership of a pollution permit, created by government regulations. If designed and implemented effectively, a tax or ETS can ensure that carbon emissions goals are met in a cost-effective manner. However, if key elements of either approach are poorly designed or implemented their functioning and effectiveness can be undermined. Requisite features of a robust and effective approach to carbon pricing include the following:

- The coverage defines the emissions of the sectors and firms, and if limited geographically, physical areas, that are subject to taxation or require a permit. Ideally the coverage should be as broad as possible to capture a diverse range of polluters. Indeed, an ETS works on the principle that mitigation is undertaken by firms with the lowest mitigation costs and total mitigation costs will be minimised with the broadest possible coverage. If necessary, coverage can be altered over time, beginning, for example, with a relatively narrow range of heavily polluting firms or industries and then expanding.

- $\quad$ Effective and reliable monitoring, reporting and verification systems are essential. As with any other kind of market, the effective operation of an ETS is dependent on the availability of pertinent information. Unreliable or incomplete information creates uncertainty, threatens smooth operation and could ultimately undermine confidence, and therefore the durability, of a scheme. Likewise, inadequate information could hinder carbon tax collection.

- A clearly specified system of sanctions enforced in a transparent and rigorous manner is needed to penalise firms which do not meet their carbon tax liabilities or fail to hold adequate permits to meet their emissions under an ETS. In the case of an ETS, such penalties must be set at a level exceeding the value of the shortfall in permits in order to provide an incentive for firms to hold sufficient permits.

In addition, an ETS requires a clearly defined target, which creates scarce rights to pollute and a price for pollution, and a mechanism for allocating permits.

- The target can be set as a cap, defined in physical units, which sets a ceiling on the total allowable emissions for a given period. Alternatively, a relative (rate based) target can be set whereby emissions per unit of output are required to fall by a specified amount. Under this configuration, a firm exceeding the required intensity target is entitled to an allocation of valuable credits while firms failing to meet the target are required to purchase these credits.

- The allocation, or method for distributing permits to polluters, has important implications for wealth distribution given that permits have value. A free allocation of permits bestows firms a valuable asset whereas requiring firms to pay for their initial permits implies the public, through the government, are compensated for granting firms the right to pollute. A free allocation can be grandfathered, where permits are distributed on the basis of past emissions, or on the basis of a benchmark, such as an industry average. Alternatively, the government can sell permits through an auction. A third option is to distribute a portion of the permits freely and auction the remainder.

Source: Reinaud and Philibert (2007). 
As noted, a diverse range of market-based and other policy tools has been used by the Chinese authorities, which can be an effective way to achieve environmental policy objectives. However, if not designed and implemented correctly, overlapping policies and tools can reduce the potency of marketbased policies and raise mitigation costs. For example, mandating technology standards with a view to reducing emissions that are also covered by a trading scheme reduces the scope for firms to select the least costly mitigation method. In this regard it is telling that the highly successful United States' $\mathrm{SO}_{2}$ ETS largely avoided imposing supplementary mandates (Chan et al., 2012). A further consideration in designing an efficient and effective trading scheme are interactions with taxes and charges that directly or indirectly penalise the same emissions. In the case of a $\mathrm{CO}_{2}$ trading scheme an additional instrument would include any form of fossil fuels tax. Assuming that a trading scheme is binding, in that emissions are capped at a level below what would prevail in the absence of any policy intervention, the co-existence of additional instruments can make these instruments redundant from the point of view of reducing total emissions (OECD, 2011c). For example, the introduction of new taxes and charges or increases in existing ones in the presence of a trading scheme would simply reduce demand for permits and push down the equilibrium price for permits and leave the total level of emissions unchanged. This calls for relevant taxes and other measures to be designed in a manner that provides consistent incentives for pollution mitigation.

An analysis of the impact of carbon pricing using a CGE model of the Chinese economy shows that the introduction of a modest carbon price of CNY 10 per tonne and recycling the revenues as tax cuts would, over the medium term, reduce emissions by around $1 \%$ compared with a business-as-usual baseline and leave the level of GDP largely unchanged (Box 3). A higher carbon price would thus be needed to meet the policy goal of substantially reducing carbon intensity over the coming years. The results also highlight that as with any other reform that causes a change in relative prices, carbon pricing would lead to a reallocation of resources across the economy with relatively carbon-intensive sectors contracting and others expanding. It would also help promote further domestic and external rebalancing, thereby supporting broader policy objectives.

As noted a pricing regime could be established with either an ETS or a tax which are equivalent with perfect competition and foresight (OECD, 2009). Even with perfect competition though, each instrument offers advantages and disadvantages which may affect the optimal policy choice in the Chinese context. While a tax offers certainty regarding the cost of pollution it can be difficult to know exactly how agents will respond to its introduction and therefore the precise impact on emissions. In contrast, a cap imposed under an ETS ensures certainty regarding the maximum level of emissions but the price of carbon, and therefore the impact on agents is, ex ante, unknown. A tax may offer a lower administrative burden given the additional complexities associated with regulating a trading scheme, a not insignificant advantage in China given the difficulties faced hitherto.

Depending on the experience with the carbon trading pilots it may be preferable to adopt a staged approach to carbon pricing whereby fossil fuels taxation is first reformed and then broadened to a carbon tax. Carbon trading, ideally eventually linked to other international schemes, could be implemented at a later stage. Irrespective of the approach taken to pricing carbon, given the important contribution from the electricity generation sector it is critical to allow increases in electricity prices in line with changes in generation costs (IEA, 2012e). In addition to moving ahead with carbon pricing, the system of pollution levies needs to be transformed into a system of pollution taxes with revenues collected by tax authorities and allocated to government coffers rather than earmarked to environmental projects. Such changes would ensure a stronger legal basis for enforcement as well as providing improved incentives for collection. At the same time levy rates should be hiked to provide stronger incentives for mitigation and a commitment made to adjust them frequently to account for inflation and changes in pollution and mitigation costs. 


\section{Box 3. Assessing the impact of carbon pricing in China}

Like any major reform, the introduction of carbon pricing can have wide-ranging economic effects. By altering production and energy costs it changes the relative prices of goods and services. This in turn leads to changes in demand across different sectors and a reallocation of resources, including capital and labour. Some areas of the economy would contract while others would typically expand. The effects of carbon pricing in China are examined here using a computable general equilibrium model of the Chinese economy developed jointly by the State Information Center of the Chinese government with help from Monash University. The model is based on the 2007 input-output table of the Chinese economy and features 137 production sectors. Production is based on inputs of capital, energy, labour and land, where labour is differentiated to account for workers with different skills while primary energy is supplied as either coal or a hybrid of oil and gas. There is substitutability between different factors of production including different types of energy.

The impact of a carbon price of CNY 10 per ton is considered under two scenarios both of which suggest the overall medium-term impact on the economy would be relatively muted. In each scenario full pass-through of carbon pricing to electricity prices is assumed. In the first, GDP is around $0.1 \%$ lower compared with the baseline assumption of no carbon price (and no specific command-and-control policies), implying only slightly lower short-run growth, while carbon emissions fall by just over $1 \%$ relative to the baseline (Figure 14A). Domestic prices rise, leading to an appreciation of the real exchange rate. Consumption falls, as does domestic investment, reflecting a decline in the real rate of return. Overall employment is just under $0.2 \%$ lower relative to the baseline. As expected carbon pricing has a stronger negative impact in energy-intensive sectors, with coal mining and power generation declining by around $1.1 \%$ and $0.7 \%$ respectively (Figure $14 \mathrm{~B}$ ).

In the second scenario carbon pricing is assumed to be revenue neutral so that the windfall to the government is recycled back into the economy through a reduction in consumption taxes. The overall impact is more muted than under the first scenario, with GDP declining only marginally, while the decline in carbon emissions is only slightly smaller. One of the main reasons for the different overall impact under this alternative scenario is that consumption rises in response to the tax cut, thereby improving the domestic balance of the economy and boosting production in some sectors. Employment is pushed up as labour is substituted for energy. Externally, the trade surplus falls. In addition, output in light manufacturing and the services sector (other than transport and wholesale trade) increases, while it declines in more energy and capital-intensive industries.

Figure 14. Impact of carbon pricing on the Chinese economy: a simulation

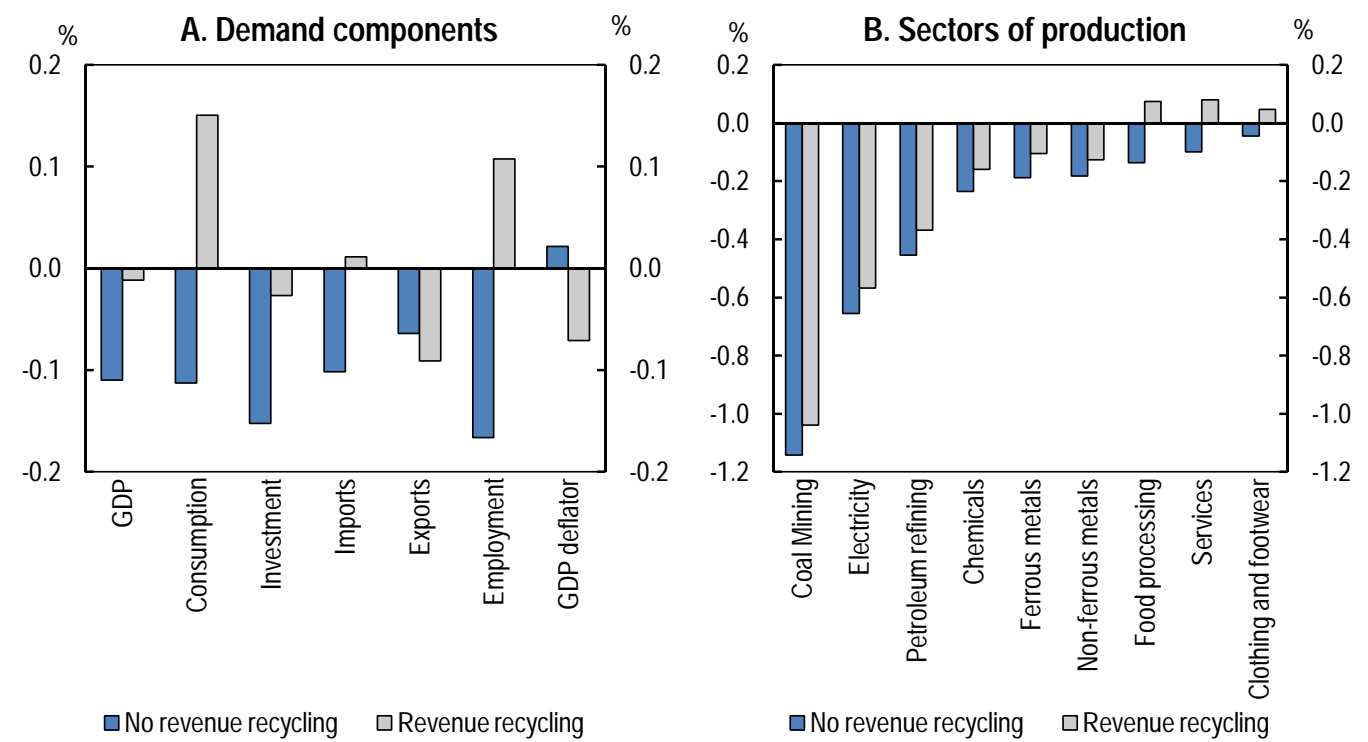

Note: Changes relative to a baseline without carbon pricing are shown. Services refers to services other than wholesale trade and transport.

Source: State Information Center. 
Implementing an effective strategy for pricing carbon and other pollutants would support the expansion of renewable energy. In several OECD countries this is often complemented by other measures and, as noted, China has taken a multi-pronged approach to expanding renewable energy, including the introduction of FITs for solar and wind power. A guiding principle for setting FITs is that the implied subsidy should be consistent with the cost of the pollution they aim to mitigate. In this regard FITs in China are relatively modest though still sufficiently generous to support new investment (IEA, 2011a). Going forward, until a more comprehensive framework for pollution pricing is implemented an appropriate level of support ought to be provided for renewable energy consistent with environmental objectives. At the same time problems that have impeded the efficient expansion of renewable energy, particularly poorly coordinated wind power projects, need to be addressed. In this respect some improvements have already been made. The approvals process for all new wind projects has been centralised, which should help avoid past problems associated with local governments authorising developments without due regard to grid connectivity (Ni and Yang, 2012). However, more fundamental issues including management of variable power loads and facilitating national transmission of electricity will require a well coordinated approach to grid management and expansion (IEA-ERI, 2011).

\section{Effective planning and strong standards are also needed}

\section{Well-planned cities are an important part of a long-term environmental and urbanisation strategy}

As noted, urbanisation rates remain relatively low by international standards but are on a rising trend. As cities expand, it is important that policy frameworks address possible adverse environmental and other effects associated with urbanisation such as congestion and the concentration of pollution and waste. Policies that promote green cities will not only serve narrow environmental objectives but economic and urbanisation goals as well. Workers will be drawn to cleaner and more attractive cities and conversely may demand compensation for working in a polluted and less attractive environment, thereby adding to costs faced by firms. This is likely to be especially true for highly-skilled workers needed to ensure the development of higher value added service industries, who tend to be more mobile. Indeed there is evidence that higher levels of pollution in Chinese cities depress property prices (Zheng et al., 2011). There are many factors which influence urban air quality, including local policies, geography and economic structures. In China, there is not always a clear relationship between city size and air pollution suggesting that the growth of large cities does not necessarily lead to poorer air quality in urban areas (Figure 15). While ambient NOx concentrations do tend to increase with population, likely reflecting higher motor vehicle use, $\mathrm{SO}_{2}$ and PM10 concentrations and overall air quality show little relationship with city size.

International experience shows that a key determinant of the environmental performance of a city is its urban form and in particular population density (OECD, 2012c). When carefully planned and developed, compact cities can offer several advantages. First, shorter travel distances, increased financial viability for public transport and a reduced dependency on motor vehicles lead to energy savings and lower air pollution. Second, higher density can result in better energy efficiency for buildings and public services and improve the feasibility of using combined power generation and central heating systems as well as smart grids which can offer potential for energy savings. Third, compact cities allow for a better use of land resources, conserving farmland and natural reserves in areas nearby cities while avoiding fragmented land use within the urban core. Fourth, compact cities offer advantages as regards mobility, access to social services and quality of life. Finally, access to well designed and reliable transport systems can lower congestion and reduce operating costs for firms and commuting times.

Recent empirical evidence for major Chinese cities suggests that compactness, assessed using different metrics including population density, is associated with stronger environmental performance and superior energy efficiency (Liu et al., 2012). Most carbon emissions in urban areas in China come from 
industrial use including power generation and in selected cities such emissions are high compared to cities in other countries (Sugar et al., 2012; Wang et al., 2012b). However, the density of Chinese cities has helped limit carbon emissions from non-industrial sources, including transport. As urbanisation continues density in Chinese cities has remained high by international standards (Herd et al., forthcoming). Going forward, sound planning together with strong investment in public transport will support environmental and other objectives.

Figure 15. Population and air pollution in Chinese cities
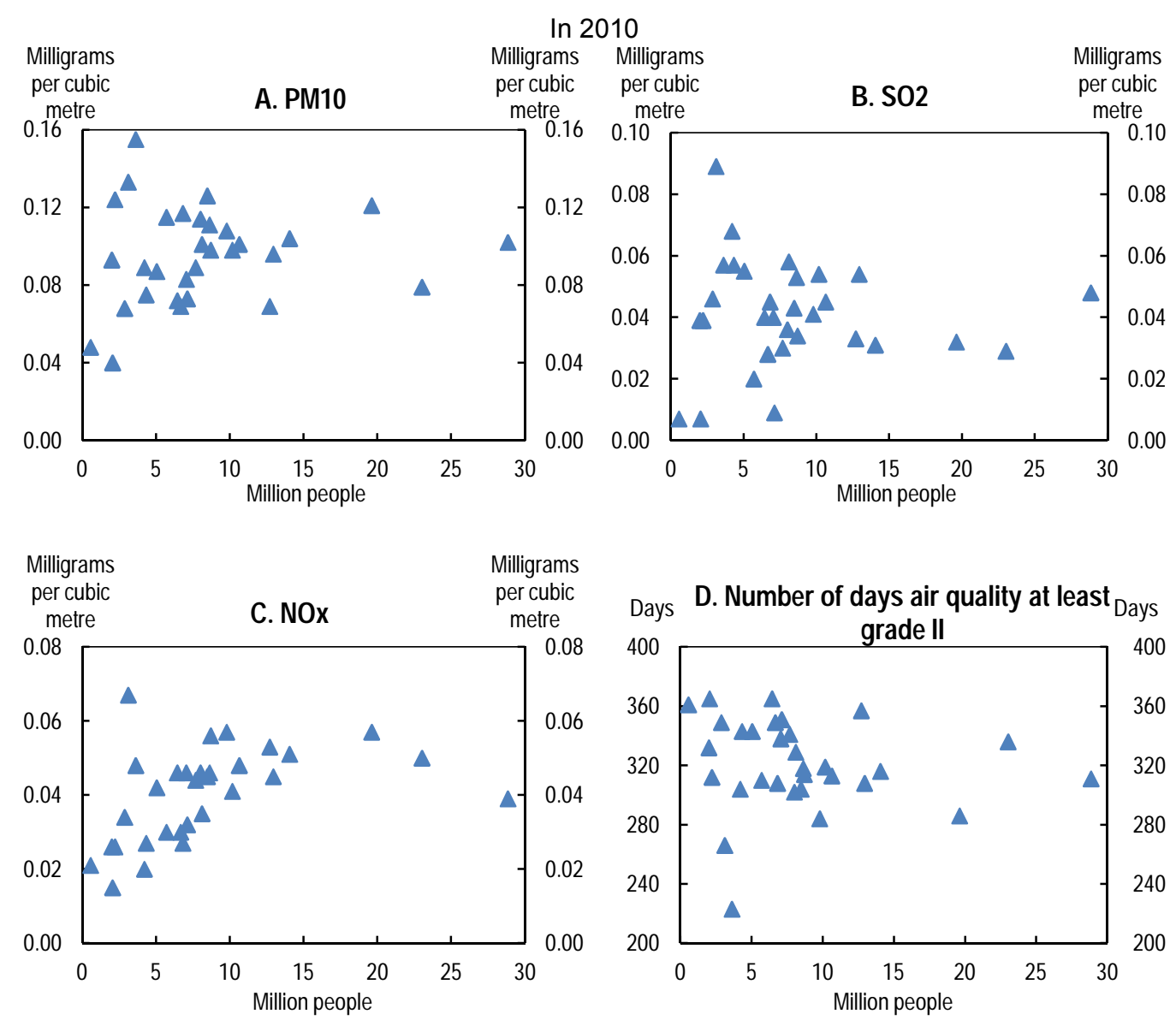

Note: Population figures include urban districts only.

Source: China Statistical Yearbook.

\section{Better environmental standards and practices are needed to complement market-based approaches}

Motor vehicle ownership rates in China remain low by international standards but have been rising rapidly (Figure 16A). China has surpassed the United States as having the largest market for new motor vehicles and may have the largest fleet in the world within a decade (Figure 16B) (Huo and Wang, 2012). Mindful of the implied environmental challenge, the government has adopted measures to control motor vehicle energy consumption and associated pollution emissions. Some, including lower sales tax rates for more fuel-efficient cars, apply nationally. In other areas the largest and most economically advanced cities and regions are taking the lead (Hao et al., 2011). Shanghai has a well established system of discouraging motor vehicle purchases by limiting the number of new registrations and auctioning new license plates. Strict limits and rising incomes have seen the average price of licence plates rise significantly, reaching over CNY 64000 (\$10 000) by mid-2012. In Beijing, policies to restrict motor vehicle use first introduced for the 2008 Olympic Games have been preserved with the current policy preventing the same motor 
vehicle from being used every day of the week. In 2012, Guangzhou followed suit implementing a mixed lottery and auction system.

However, there is evidence that loopholes are being exploited with these measures, for example Shanghai residents sometimes register their vehicles in neighbouring cities to reduce registration costs (Wang, 2010). A further downside to these approaches is that they are likely less efficient than other measures which directly increase the cost of motor-vehicle use. Where governments wish to continue rationing licence plates, allocation through an auction would be preferable as it is more economically efficient than a lottery system. Better still would be focusing on measures that target motor vehicle use such as raising fuel excise rates and implementing congestion charges, as has been done in some countries including Singapore and Sweden (OECD-ITF, 2010).

Figure 16. Motor vehicle ownership rates and sales

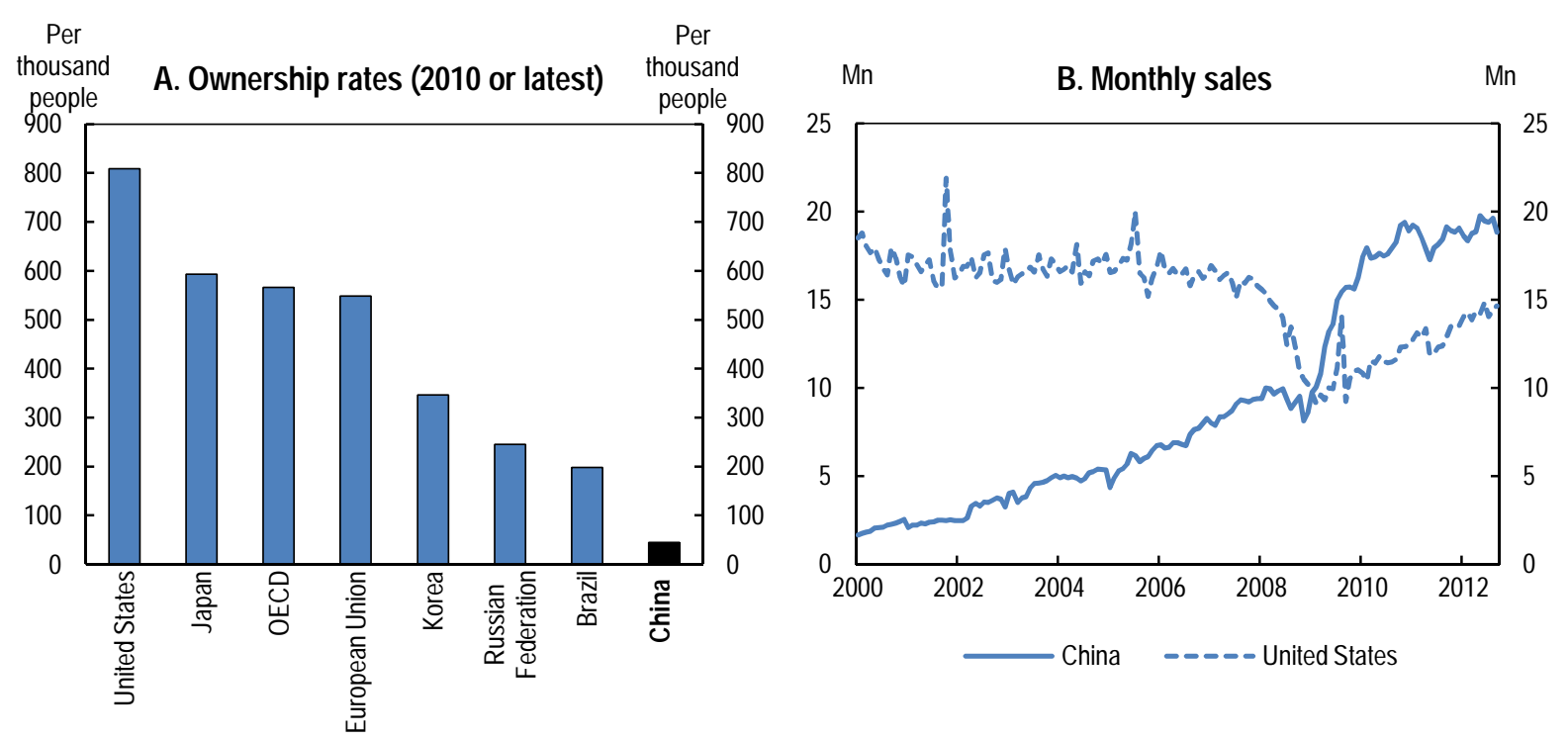

Source: CEIC, Datastream and World Development Indicators.

As in OECD countries, an important element of the strategy to control motor vehicle pollution in China has been the implementation of emissions standards for new light and heavy-duty motor vehicles. A national system based on the EU "Euro" standards was established in 2000 followed by successively more stringent standards specifying lower permissible emissions of key pollutants. A national roll-out of the China IV standard, similar to the Euro V standards introduced in 2009, is now underway and in a number of more economically advanced parts of the country, including Beijing, an even more stringent China $\mathrm{V}$ standard is being planned. The evidence suggests that the gradual tightening of emissions standards in Beijing has been by far the most important factor in reducing motor vehicle emissions of key pollutants such as CO, hydrocarbons, NOx and PM in the context of a rapidly expanding motor vehicle fleet (Wu et al., 2011). Indeed, without these measures such emissions would have continued to rise through the 2000 s with attendant adverse effects on local air quality and health. Nationally, the importance of higher standards is further underscored by the disproportionately large air pollution emissions from older, lower standard motor vehicles. Though comprising less than $13 \%$ of the national fleet in 2010, pre-China I standard vehicles emitted more than half of all motor vehicle related PM pollution (MEP, 2011c).

While higher emissions standards help contain pollution, their effectiveness depends on the quality of diesel and gasoline. Many motor vehicle technologies that limit NOx and PM emissions work best with low sulphur fuels, and in the case of diesel particulate filters the leading technical solution for reducing PM emissions from diesel vehicles require fuel with sulphur concentrations below $50 \mathrm{ppm}$ (Sharpe et al., 
2011). Some progress has been made in improving fuel quality in China, notably with the phasing out of leaded fuels in the early 2000s. However, improvements in other areas, including sulphur content, have lagged behind. The current national standard sets limits on sulphur content at $150 \mathrm{ppm}$ and $350 \mathrm{ppm}$ for gasoline and diesel respectively, although again some cities such as Beijing have successfully implemented higher standards (Ma et al., 2012). This is well above leading international benchmarks and what is needed to maximise the benefit of lower motor vehicle emission standards.

The problem with sulphur content is so acute that it has delayed the implementation of China IV emissions standards for diesel vehicles in some areas thus making it more difficult for the government to achieve its 12th FYP air pollution reduction goals, notably for NOx. This is particularly unfortunate given that diesel vehicles produce a disproportionately large share of some types of motor vehicle related pollution (MEP, 2011c). Producing cleaner fuels requires the dominant domestic refineries to invest in costly new facilities. The practice of keeping gasoline and diesel retail prices below cost has hindered the feasibility of passing on the higher cost of cleaner fuels to consumers. However, in light of the recent changes to pricing policies discussed above this now poses less of an obstacle and the government should move ahead with enforcing higher fuel standards and allowing the cost of higher quality fuels to be reflected in retail prices. At the same time promoting more competition in the refinery sector would help ensure that costs associated with the transition to cleaner fuels are minimised. The leading role played by cities such as Beijing shows how stronger emissions and fuel standards can limit motor vehicle pollution. Nationwide implementation of leading China standards, and over time higher standards still, should be a high priority for the central government.

As noted, alternative energy vehicles, including electric vehicles, is one of several strategic industries the government is actively promoting and represents another response to the challenge posed by rising transport sector energy use and pollution. While electric vehicles do not produce air pollution directly, their environmental benefit depends largely on how and where the electricity they consume is generated. If renewable energy and other cleaner energy sources comprise a significant share of the underlying electricity supply mix then electric vehicles have the potential to reduce pollution significantly. However, if electricity supply is dominated by dirtier sources such as coal, as in China, electric vehicles could potentially exacerbate air pollution problems. Indeed, because of the reliance on coal a recent analysis focussing on Chinese cities found that pollution emissions from electric vehicles were higher than conventional gasoline vehicles (Ji et al. 2012). Moreover, even after accounting for the closer proximity of emissions from conventional vehicles, electric vehicle use was estimated to account for more premature deaths, casting serious doubt on the merit of current policies promoting their use.

Energy consumed by buildings in China has lagged behind many OECD countries, reflecting both a lower per-capita built-up area and lower energy usage per unit of floor space on account of different norms concerning temperature regulation Zhang et al., 2010b). However, with ongoing urbanisation and expected increases in absolute and per-capita residential and commercial building space, promoting energy-efficient buildings will be important. Since the 1990s China has developed a mandatory energy efficiency standards system for new buildings which has been gradually upgraded in different parts of the country. Low compliance has proved a problem in the past, with only around half all new buildings meeting standards at the design stage and less than a quarter at the construction stage in 2005 (Bin and Jun, 2012). In response, the Ministry of Housing and Rural and Urban Development (MHRUD) launched a new inspection system covering most provinces and by 2010 compliance rates at both design and construction stages had risen above $95 \%$. The government has now launched a programme to ensure that by $2015,20 \%$ of all new buildings will meet new higher efficiency standards.

Alongside these efforts, standards for consumer durable energy efficiency have been strengthened (Yuan et al., 2011). In 2005 the government introduced an energy efficiency labelling system for airconditioners and refrigerators which has since been broadened to cover a larger range of goods and 
modified to incorporate some mandatory standards. More recently the government banned the sale of 100-watt or greater incandescent light bulbs (NDRC, 2012).

Mandatory building efficiency requirements have been complemented by a rise in voluntary green building certification systems of the kind that exist in OECD countries. The two leading schemes in China are the Three Star system developed by the MHRUD and the Leadership in Energy and Environmental Design system, which originated in the United States. Though the number of construction projects earning certification under these systems remains relatively low, it has increased rapidly and they offer significant potential to encourage green property development as they have in OECD countries. Such schemes can complement mandatory standards by providing an incentive for property developers to respond to market demands for higher energy and environmental standards. In the same way, industry-based standards can also help encourage further energy-enhancing retrofitting. Governments can also play a facilitating role by filling information gaps through the initiation of building energy audits which can be used as the basis for energy management contracts. Under this model, which has been successfully applied in some Chinese cities, third-party firms finance retrofitting of energy conservation and are allocated the financial windfall of lower energy costs in return.

\section{Enforcement and implementation capacity need to be enhanced}

The legal framework for environmental protection in China has evolved to encompass a comprehensive range of laws (McElwee, 2011). In addition, existing core legislation has been modernised and amended, and new regulations implemented to reflect evolving environmental needs. Recent revisions to the Civil Procedure Law also open the door to stronger environmental enforcement (Song and Ye, 2012). The increased importance attached to environmental issues is reflected in the evolution of institutional arrangements for environmental governance. In 2008 environmental protection was given full ministerial status when the then State Environmental Protection Administration became the Ministry of Environmental Protection. The MEP, which comprises a head office as well as six regional branches, has broad responsibility for formulating the government's environmental strategies, including input into national plans, as well as the preparation of specific policies and associated legislation. In general the MEP it is not engaged in direct oversight or enforcement issues, which are primarily the domain of local environmental protection bureaus (EPBs) which report to MEP but are ultimately controlled by local governments. The main mechanism by which national environmental goals and targets filter down to local authorities responsible for implementation and enforcement is the "Target Responsibility System" which is an agreement between one layer of government and its subordinate units specifying actions to be taken and targets to be achieved. This then forms the basis on which local officials are evaluated on environmental performance.

A key constraint in implementing environmental policies and ensuring that national goals are met relates to the sometimes conflicting incentives faced by local governments. Local EPBs are subordinate to local government directives and their ability to execute enforcement functions have at times been stymied when environmental concerns have been overridden by other imperatives. This challenge was highlighted during the roll-out of the stimulus package during the global downturn in 2008 when normal procedures for assessing environmental aspects of new development proposals were bypassed to expedite spending (Liu and Raven, 2010). Strong central government oversight has been essential for progress, notably reductions in $\mathrm{SO}_{2}$ emissions, and a continued effort is needed going forward. A further weakness in the environmental enforcement framework has been the very low fines for polluting which in the past has led some firms to choose to pay a fine rather than undertake costly mitigation. In response, the government has taken steps to strengthen penalties by raising fines and targeting individuals responsible in order to improve accountability. In the case of prosecutions involving severe environmental damage under the Law on Water Pollution Prevention and Control a dual fine applies: one component is based on economic loss associated with the damage caused, and the other on the salary of the person held responsible (Yuan and $\mathrm{Wu}, 2011)$. 
One specific area of environmental regulation highlighted as needing strengthening in the 12th FYP is nuclear and radiation safety, with an emphasis on improving the reliability of nuclear facilities and reinforcing regulatory and management capabilities. As noted above, the authorities responded quickly to events in Fukushima, reaffirming the importance given to nuclear safety. The safety audit undertaken by the government, which covered all existing facilities as well as those under construction, found that most facilities met domestic and international safety standards and no requirement to undertake any major redevelopment was identified. However, in some cases guidelines on severe accident mitigation were deemed inadequate and improvements to flood protection or resilience to earthquakes judged necessary, all of which the government has committed to addressing within a specified timeframe (Zhou, 2012).

As the nuclear sector continues to grow in China, regulatory resources need to expand and regulations need to evolve in line with international best practice. Strong and effective nuclear regulation encompasses several elements (OECD, 2011d). The envisaged expansion of the industry is unprecedented in speed and scale and effective oversight presents a major challenge (Zhou et al., 2011). As events in other sectors in China have demonstrated, rapid infrastructure expansion can entail safety problems. The number of official regulatory personnel per unit of nuclear energy produced in China is relatively low by international standards and increasing regulatory capacity in concert with the expansion of the industry raises broader problems of limited training and research capability. A further issue is ensuring that the nuclear safety regulator, the National Nuclear Safety Administration, has an adequate voice at the highest levels of government. By virtue of being part of MEP it has access to the State Council but the same is true of the three large companies which operate nuclear energy facilities, as they are SOEs. Finally, nuclear energy is governed by a framework which operates on the basis of dated regulatory instruments. Issuing a law expressly for this purpose, akin to those in many other countries with a nuclear energy industry, would provide an opportunity to update the legal framework and further clarify issues such as liability for damages incurred in the event of an accident.

\section{Better monitoring and information disclosure will also help}

The government continues to strengthen environmental monitoring capacity. A major milestone was a national pollution census undertaken in the late 2000s which involved assessing close to six million separate pollution sources spanning the full gamut of economic activities. This exercise highlighted a major gap in regular reporting of water pollution. Until the census results were published in 2010, official statistics only reported industrial and household sectors, ignoring the agriculture sector which was then found to be a major contributor of pollution. Efforts have been made to introduce more advanced technology to track industrial emissions, particularly for $\mathrm{SO}_{2}$. More recently, in $2012 \mathrm{MEP}$ conducted a pilot programme to monitor ambient mercury emissions which involved the installation of continuous monitoring equipment in thermal power generators in several provinces. Ambient air quality standards were also revised in 2012, setting lower limits for pollutants already included and broadening coverage to incorporate others, including PM2.5. This brings China closer to best practice in this area and is expected to have a measurable improvement on air quality. For example the government anticipates that the new PM2.5 guidelines will lower concentrations by at least 5\% in 13 major areas covering 117 cities.

Despite these improvements, publicly available information on some types of ambient pollution remains limited, even for pollutants included in official air quality standards (Renmin University of China Law School and IPE, 2011). Key pollutants for which data are not readily available include CO, ozone and VOCs. There is also a dearth of official data for $\mathrm{CO}_{2}$ and other GHG emissions at both the national and sub-national levels, despite the government having adopted $\mathrm{CO}_{2}$ targets for the 12th FYP and beyond. The government has committed to improved monitoring of some pollutants in the 12th FYP. Looking ahead it should specify targets for controlling emissions of a more diverse range of pollutants as part of a move towards establishing broader environmental targets based on scientific and economic analysis. 
Public awareness and interest in environmental issues has increased, particularly with regard to air quality in large cities, and environmental information disclosure is being boosted alongside improvements in monitoring. Disclosure plays an important role in raising awareness of environmental issues and promoting more effective enforcement. Polluting firms that are exposed risk suffering consumer or investor boycotts as well as litigation and therefore even the threat of information dissemination can induce better practices. A milestone in promoting improved disclosure practices was the implementation in 2008 of the national Measures on Environmental Information Disclosure. These stipulate requirements for local environmental authorities to make public information pertaining to environmental policies, plans and laws as well as blacklisted firms (Johnson, 2011). The MEP, through the China National Environmental Monitoring Center and local EPBs, makes a wide range of timely environmental indicators available through government websites, including ambient levels of pollution as well as the status of water quality in rivers and lakes. It has also committed to further improving the dissemination of such information in the coming years.

While these responses represent a step forward, implementation varies across the country and there remains room for local officials to sidestep national requirements. The national government could further strengthen efforts in this area by revising the guidelines to be more prescriptive. A further challenge relates to the way in which some information is made available to the public. One of the main tools the government uses to report air quality in cities is an official Air Pollution Index (API). Based on national standards which have evolved to encompass a broader range of pollutants, the API assigns qualitative descriptions of air quality to numerical outcomes based on prevailing pollution levels. This mechanism has also been used to determine "blue sky" days, which are counted when API values are below a threshold level and reported in official sources. The usefulness of the API hinges on the language used to describe pollution levels associated with different API levels and on this score past practice has been poor. In particular, levels of pollution deemed high by international standards, as well as the standards applied in Hong Kong, were referred to in benign terms, including "blue skies" in mainland cities. The Beijing government is leading the way with reform in this area, announcing that it would abandon the blue sky concept and instead focus on timely reporting of ambient concentrations of different pollutants.

\section{Conclusions}

Rapid economic growth focussed on manufacturing and investment has led to strong increases in energy demand, high levels of pollution and other environmental pressures. Air quality is invariably poor owing to high emissions from a range of industrial and other sources. Many lakes and rivers also suffer from severe pollution and water scarcity presents a threat in some parts of the country. These pressures entail health and other costs, warranting further environmental and related reforms. So far the government has relied heavily on command-and-control measures to reduce pollution and promote other environmental goals. In some cases these have been very costly and looking ahead more emphasis needs to be given to effective implementation of market-based reforms, complemented by other measures (Box 4).

Prices for petroleum products are relatively low and applicable excise duties should be raised to promote conservation. There is also scope to raise electricity and water prices, which could be done alongside offsetting measures to protect poorer households. Poor implementation has stymied the effectiveness of pollution pricing as a tool for supporting environmental objectives in China. Therefore, reforms are needed to strengthen the existing pollution levy system. Careful attention also needs to be paid to implementation details of pilot $\mathrm{CO}_{2}$ emissions trading schemes. Serious consideration ought to be given to the introduction of a carbon tax, especially if the administrative challenges associated with trading schemes prove difficult to address. Both types of carbon pricing, if implemented correctly, would support further growth in renewable energy. Until then an appropriate level of direct support should continue but efforts are called for to improve the efficiency of investments in this area. These reforms should be complemented by stronger standards, especially with regards to motor vehicles and fuels. Finally, 
monitoring and regulatory enforcement capacity should be enhanced, especially at the local level. In the area of nuclear energy safety it is important that regulatory capacity keeps pace with the rapid growth of the sector.

\section{Box 4. Main policy recommendations}

\section{Improve energy and water efficiency}

- Increase excise duties on gasoline and other petroleum products to bring end-user prices closer to the norm of advanced economies. Complete reforms to deregulate prices to allow full pass-through of changes in international oil prices.

- Following the conclusion of pilot schemes for market-based natural gas pricing extend arrangements nationally and move to full market-based pricing of coal. Reform prices in the power generation sector to better reflect costs including carbon and other pollution pricing. Avoid preferential electricity pricing for selected industrial users. Experiment with the separation of transmission and distribution with a view to moving towards price deregulation.

- $\quad$ Raise piped water prices to end-users to better reflect scarcity and encourage conservation. In doing so pay attention to distributional consequences and where necessary support poorer households by providing financial assistance through the minimum living allowance or direct transfers. In rural areas continue to encourage the formation of local water markets.

\section{Strengthen pollution price signals}

- Increase air and water pollution levies and strengthen their legal basis by moving towards a system of explicit pollution taxes. Promote a streamlined collection process to ease the burden on local governments and businesses.

- Ensure effective implementation of $\mathrm{CO}_{2}$ pilot emissions trading schemes. Move towards national carbon pricing, preferably by implementing a carbon tax, depending on experiences with the pilot schemes.

- Focus on measures that directly discourage motor vehicle use, including congestion charges, rather than license plate rationing, as a way to reduce associated externalities.

\section{Provide appropriate support to renewable energy investment}

- Until effective national $\mathrm{CO}_{2}$ pricing is established, and the pollution levy system strengthened, continue to provide assistance to renewable energy investment at a level consistent with carbon reduction and other environmental goals. Avoid providing more support to one type of renewable energy source. Address supply bottlenecks with wind and solar energy and continue to promote improved investment coordination and grid connectivity.

\section{Raise environmental standards and improve enforcement and implementation}

- $\quad$ Continue to improve national standards for motor vehicles and fuels, especially regarding sulphur content, by extending high standards in leading cities across the country. Gradually phase in still stronger standards in line with technological advances and international best practice.

- Establish targets for a broader range of environmental objectives, including additional air and water pollutants, based on scientific and economic analysis and continue to ensure that local governments are held responsible for achieving environmental objectives. Improve national data collection and dissemination of all major pollutants including $\mathrm{CO}_{2}$ and other greenhouse gases.

- $\quad$ Strengthen nuclear energy safety including by increasing regulatory capacity to keep pace with rising nuclear energy investment. Update regulatory framework to provide clearer accountability and ensure regulatory authorities have direct access to the highest levels of government. 


\section{Bibliography}

Bao, L. J. Zhao and N. Zhu (2012), “Analysis and Proposal of Implementation Effects of Heat Metering and Energy Efficiency Retrofit of Existing Residential Buildings in Northern Heating Areas of China in the 11th Five-Year Plan' Period", Energy Policy, Vol. 45.

Baumgartner, J., J-J. Schauer, M. Ezzati, L. Lu, C. Cheng, J-A. Patz and L-E. Bautista (2011), "Indoor Air Pollution and Blood Pressure in Adult Women Living in Rural China", Environmental Health Perspectives, Vol. 199.

Beirne, J., G. Liu and L. Zhang (2012), "Electricity Pricing in China and the Role of the State", Economics Bulletin, Vol. 32.

Bin, S. and L. Jun (2012), Building Energy Efficiency Policies in China, Status Report, Global Buildings Performance Network.

Cao, G-L., X-Y. Zhang, S-L. Gong, X-Q. An and Y-Q. Wang (2011), "Emission Inventories of Primary Particles and Pollutant Gases for China", China Science Bulletin, Vol. 56.

CCICED (2009), Economic Instruments for Energy Efficiency and the Environment, Policy Research Report 2009, Beijing.

CCICED (2011), Assessment Report on Pollution Reduction in the 11th Five-year Plan, CCICED.

Chan, G., R. Stavins, R. Stowe and R. Sweeney (2012), "The SO2 Allowance Trading System and the Clean Air Act Amendments of 1990: Reflections on Twenty Years of Policy Innovation", NBER Working Papers, No. 17845.

Chang, Y. and N. Wang (2010), "Environmental Regulations and Emissions Trading in China", Energy Policy, Vol. 38.

Chen, J. (2011), “China's Experiment on the Differential Electricity Pricing Policy and the Struggle for Energy Conservation", Energy Policy, Vol. 39.

Columbia Earth Institute, Yale University and Battelle Institute (2012), The Environmental Performance Index.

Ebenstein, A. (2012), “The Consequences of Industrialization: Evidence from Water Pollution and Digestive Cancers in China", The Review of Economics and Statistics, Vol. 94.

Economy, E. (2010), When the River Runs Black, the Environmental Challenge to China's Future, Cornell University Press, Ithaca.

EPA (2012), Report to Congress on Black Carbon, EPA, Washington D.C.

Fisher-Vanden, K., E. Mansur and Q. Wang (2012), “Costly Blackouts? Measuring Productivity and Environmental Effects of Electricity Shortages”, NBER Working Papers, No. 17741.

Freeman, C. (2011), "Quenching the Dragon's Thirst, The South-North Water Transfer Project-Old Plumbing for New China?", China Environment Forum Brief, Woodrow Wilson International Center for Scholars.

Ge, C., S. Gao, Y. Ren, G. Sun and F. Long (2011), "Study on the Design of Wastewater Environmental Tax in China: from Wastewater Pollutant Discharge Fee to Environmental Tax", in L. Kreiser, J. Sirisom, H. Ashiabor and J. Milne (eds.) Environmental Taxation in China and Asia-Pacific, Achieving Environmental Sustainability through Fiscal Policy, Edward Elgar, Northampton. 
Gleik, P. (2009), “China and Water”, in P. Gleik (ed.), The World's Water 2008-2009: The Biennial Report on Freshwater Resources, Pacific Institute for Studies in Environment, Development Security.

Guerin, E. and X. Wang (2012), "Mitigation Targets and Actions in China up to 2020: Progress Towards the 2020 Carbon Intensity Target, Allocation of Provincial Targets, Design of Carbon Market Pilots, and Links with Broader Socio Economic Objectives", IDDRI Working Papers, No. 01/12.

Hao, H., H. Wang and M. Ouyang (2011), "Comparison of Policies on Vehicle Ownership and Use Between Beijing and Shanghai and their Impacts on Fuel Consumption by Passenger Vehicles", Energy Policy, Vol. 39.

He, G., A. Mol and Y. Lu (2012), “Trust and Credibility in Governing China’s Risk Society", Environmental Science and Technology, Vol. 46.

Herd, R., T. Chalaux and V. Koen (forthcoming), "Policies for Inclusive Urbanisation in China", OECD Economics Department Working Paper.

Huo, H. and M. Wang (2012), "Modeling Future Vehicle Sales and Stock in China”, Energy Policy, Vol. 43.

IEA (2009), Cleaner Coal in China, IEA, Paris.

IEA (2010), World Energy Outlook 2010, IEA, Paris.

IEA (2011a), Deploying Renewables 2011, Best and Future Policy Practice, IEA, Paris.

IEA (2011b), World Energy Outlook 2011, IEA, Paris.

IEA (2012a), CO2 Emissions from Fuel Combustion, IEA, Paris.

IEA (2012b), Coal Information, 2012, IEA, Paris.

IEA (2012c), Golden Rules for a Golden Age of Gas, IEA, Paris.

IEA (2012d), Oil and Gas Security, Emergency Response of IEA Countries - People's Republic of China, IEA, Paris.

IEA (2012e), Policy Options for Low Carbon Power Generation in China - Designing an Emissions Trading System for China's Electricity Sector, IEA, Paris.

IEA-ERI (2011), Technology Roadmap, China Wind Energy Development Roadmap 2050, IEA, Paris.

Information Office of the State Council (2011), China's Policies and Actions for Addressing Climate Change, Information Office of the State Council, Beijing.

Information Office of the State Council (2012), China's Energy Policy 2012, Information Office of the State Council, Beijing.

Ji, S., C. Cherry, M. Bechle, Y. Wu and J. Marshall (2012), "Electric Vehicles in China: Emissions and Health Impacts", Environmental Science and Technology, Vol. 46.

Jianrong, Q. (2011), “Alarming Environment and Health Incidents in 2009”, in Dongping, Y. (Ed.) The China Environment Yearbook Volume 5, Brill, Boston.

Jinnan, W., D. Zhanfeng, Y. Jintian, L. Yunsheng and Y. Gang (2009), "Practices and Prospects of Emission Trading Programs in China", Chinese Academy For Environmental Planning mimeo.

Johnson, T. (2011), "Environmental Information Disclosure in China: Policy Developments and NGO Responses", Policy and Politics, Vol. 39. 
Kan, H. (2011), "Climate Change and Human Health in China", Environmental Health Perspectives, Vol. 119.

Li, W., M. Beresford and G. Song (2011), "Market Failure or Governmental Failure? A Study of China's Water Abstraction Policies", The China Quarterly, Vol. 208.

Lin,W., X. Xu, B. Ge and X. Liu (2011), "Gaseous Pollutants in Beijing Urban Area during the Heating Period 2007-2008”, Atmospheric Chemistry and Physics, Vol. 11.

Lin, B. and Z. Jiang (2011), "Estimates of Energy Subsidies in China and Impact of Energy Subsidy Reform”, Energy Economics, Vol. 33.

Lin, C. and J. Zeng (2012a). "The Elasticity of Demand for Gasoline in China", University of California at Davis Working Paper.

Lin, C. and J. Zeng (2012b), "The Optimal Gasoline Tax for China”, University of California at Davis Working Paper.

Liu, W. (2012), "The Expectations and Worries behind the New Drinking Water Quality Standard", Journal of China National People's Congress, Vol. 13.

Liu, G. and L. Zhang (2012), "Understanding the Performance of the Electric Power Industry in China", Asian Economic Papers, Vol. 11.

Liu, J. and P. Raven (2010), "China's Environmental Challenges and Implications for the World", Critical Reviews in Environmental Science and Technology, Vol. 40.

Liu, Y., Y. Song and H. Arp (2012), "Examination of the Relationship Between Urban Form and Urban Eco-efficiency in China", Habitat International, Vol. 36.

Ma, J. (2011), “On-grid Electricity Tariffs in China: Development, Reform and Prospects”, Energy Policy, Vol. 39.

Ma, L., F. Fu, Z. Li and P. Liu (2012), "Oil Development in China: Current Status and Future Trends", Energy Policy, Vol. 45.

Matus, K., K. Nam, N. Selin, L. Lamsal, J. Reilly and S. Paltsev (2012), "Health Damages from Air Pollution in China", Global Environmental Change, Vol. 22.

McElwee, C. (2011), Environmental Law in China, Oxford University Press, New York.

Medianu, D. and J. Whalley (2012), "Water Availability as a Constraint on China's Future Growth", NBER Working Papers, No. 18124.

MEP (2011a), 2010 Annual Statistic Report on Environment in China, MEP, Beijing.

MEP (2011b), 2010 State of the Environment, MEP, Beijing (in Chinese).

MEP (2011c), China Vehicle Emission Control Annual Report 2011, MEP, Beijing (in Chinese).

MEP (2012), 2011 State of the Environment, MEP, Beijing (in Chinese).

MRW (2011), 2010 Statistic Bulletin on China Water Activities, MRW, Beijing.

Nakano, S., A. Okamura, N. Sakurai, M. Suzuki, Y. Tojo and N. Yamano (2009), "The Measurement of CO2 Embodiments in International Trade: Evidence from the Harmonised Input-Output and Bilateral Trade Database", OECD Science, Technology and Industry Working Papers, No. 3. 
National Energy Conservation Center (2011), From 11th FYP to 12th FYP, China's Achievements and Priorities in the Field of Energy Conservation, National Energy Conservation Center, Beijing.

NBS-MEP (2011), China Statistical Yearbook on Environment, 2011, China Statistics Press, Beijing.

Ni, M. and Z. Yang (2012), "By Leaps and Bounds, Lessons Learned from Renewable Energy Growth in China", IEEE Power and Energy Magazine, March-April.

Nicholls, R., S. Hanson, C. Herweijer, N. Patmore, S. Hallegatte, J. Corfee-Morlot, J. Chateau, R. MuirWood (2008) "Ranking Port Cities with High Exposure and Vulnerability to Climate Extremes: Exposure Estimates", OECD Environment Working Papers, No. 1.

NDRC (2012), China's Policies and Actions for Addressing Climate Change, NDRC, Beijing.

OECD (2008), OECD Environmental Outlook to 2030, OECD, Paris.

OECD (2009), The Economics of Climate Change Mitigation, Policies and Options for Global Action Beyond 2012, OECD, Paris.

OECD (2010a), OECD Economic Surveys: China, OECD, Paris.

OECD (2010b), Pricing Water Resources and Water and Sanitation Services, OECD, Paris.

OECD (2011a), Regions at a Glance 2011, OECD, Paris.

OECD (2011b), Towards Green Growth, OECD, Paris.

OECD (2011c), "Interactions between Emission Trading Systems and Other Overlapping Policy Instruments", General Distribution Document, Environment Directorate, OECD, Paris.

OECD (2011d), Improving Nuclear Regulation, NEA Regulatory Guidance Booklets Volumes 1-14, OECD, Paris.

OECD (2012a), OECD Environmental Outlook to 2050, the Consequences of Inaction, OECD, Paris.

OECD (2012b), Energy, Green Growth Studies, OECD, Paris.

OECD (2012c), Compact City Policies: A Comparative Assessment, OECD, Paris.

OECD-ITF (2010), Implementing Congestion Charges, OECD, Paris.

Pew (2012), Who's Winning the Clean Energy Race? 2011 Edition, The Pew Charitable Trusts.

Qin, Y. and S. Xie (2012), "Spatial and Temporal Variation of Anthropogenic Black Carbon Emissions in China for the Period 1980-2009”, Atmospheric Chemistry and Physics, Vol. 12.

Ranson, M. and R. Stavins (2012), "Post-Durban Climate Policy Architecture Based on Linkage of Capand-Trade Systems, NBER Working Papers, No. 18140.

Reinaud, J. and C. Philibert (2007), Emissions Trading: Trends and Prospects, IEA, Paris.

Renmin University of China Law School and IPE (2011), Air Quality Information Transparency Index - A Threat to Public Health: China's Urban Air Quality Disclosure Needs Urgent Improvement, Renmin University of China Law School and IPE, Beijing.

Saikawa, E., V. Naik, L. Horowitz, J. Liu and D. Mauzerall (2009), "Present and Potential Future Contributions of Sulphate, Black and Organic Carbon Aerosols from China to Global Air Quality, Premature Mortality and Radiative Forcing", Atmospheric Environment, Vol. 43. 
Schreifels, J., Y. Fu and E. Wilson (2012), "Sulfur Dioxide Control in China: Policy Evolution During the 10th and 11th Five-year Plans and Lessons for the Future", Energy Policy, Vol. 48.

Sharpe, B., F. Fung, F. Kamakate, F. Posada and D. Rutherford (2011), "Developing a World Class Technology Pathways Program in China - International Practices for Vehicle Emission Standards", The International Council on Clean Transportation White Paper, No. 14.

Song, Y. and A. Ye (2012), "Justice, Efficiency and the New Civil Procedure Law", China Law and Practice, November-December 2012.

State Council (2012), National "12th Five-Year Plan" for Environmental Protection, China Environmental Science Press, Beijing.

Sugar, L., C. Kennedy and E. Leman (2012), "Greenhouse Gas Emissions from Chinese Cities”, Journal of Industrial Ecology, Vol. 16.

Suthawaree, J., S. Kato, P. Pochanart, Y. Kanaya, H. Akimoto, Z. Wang and Y. Kajii (2012) "Influence of Beijing Outflow on Volatile Organic Compounds (VOC) Observed at a Mountain Site in North China Plain", Atmospheric Research, Vol. 111.

Wang, R. (2010), “Shaping Urban Transport Policies in China: Will Copying Foreign Policies Work?”, Transport Policy, Vol. 17.

Wang, W. (2011), "Greening the Dragon: Energy Tax Policy in China”, in L. Kreiser, J. Sirisom, H. Ashiabor and J. Milne (eds.) Environmental Taxation in China and Asia-Pacific, Achieving Environmental Sustainability through Fiscal Policy, Edward Elgar, Northampton.

Wang, H. and D. Wheeler (2005), "Financial Incentives and Endogenous Enforcement in China's Pollution Levy System", Journal of Environmental Economics and Management, Vol. 49.

Wang, J., J. Huang, S. Rozelle, Q. Huang and L. Zhang (2009), "Understanding the Water Crisis in Northern China: What the Government and Farmers are Doing", International Journal of Water Resources Development, Vol. 25.

Wang, J., Y. Lei, J. Yang and G. Yan (2012a), "China's Air Pollution Control Calls for Sustainable Strategy for the Use of Coal”, Environmental Science and Technology, Vol. 46.

Wang, H., J. Bi, R. Zhang and M. Liu (2012b), "The Carbon Emissions of Chinese Cities”, Journal of Atmospheric Chemistry and Physics, Vol. 12.

WHO-UNICEF (2012), Estimates for the Use of Improved Drinking-Water Sources, China, WHO and UNICEF.

World Bank (2012), State and Trends of the Carbon Market, 2012, World Bank, Washington D.C.

World Bank-DRC (2012), China 2030: Building a Modern, Harmonious, and Creative High-Income Society, World Bank, Washington D.C.

Wu, X. (2012a), "Why China, US argue over PM2.5 data”, People's Daily Online accessed from http://english.peopledaily.com.cn/90882/7839960.html.

Wu, Y. (2012b), “Energy Intensity and its Determinants in China's Regional Economies”, Energy Policy, Vol. 41.

Wu, Y., R. Wang, Y. Zhou, B. Lin, L. Fu, K. He and J. Hao (2011), "On-Road Vehicle Emission Control in Beijing: Past, Present and Future", Environmental Science and Technology, Vol. 45. 
Xiaoqing, W. (2012), "Wu Xiaoqing's speech”, speech delivered by Vice Minister of Ministry of Environmental Protection accessed from www.china.org.cn.

Xu, J., J-Z. Ma, X-L. Zhang, X-B. Xu, X-F. Xu, W-L. Lin, Y. Wang, W. Meng and Z-Q. Ma (2011), "Measurements of Ozone and its Precursors in Beijing During Summertime: Impact of Urban Plumes on Ozone Pollution in Downwind Rural Areas", Atmospheric Chemistry and Physics Discussions, Vol. 11.

Yang, L., X. Zhou, Z. Wang, Y. Zhou, S. Cheng, P. Xu, X. Gao, W. Nie, X. Wang and W. Wang, (2012), "Airborne Fine Particulate Pollution in Jinan, China: Concentrations, Chemical Compositions and Influence on Visibility Impairment", Atmospheric Environment, Vol. 55.

Yuan, J., J. Kang, C. Yu and Z. Hu (2011), "Energy Conservation and Emissions Reduction in ChinaProgress and Prospective", Renewable and Sustainable Energy Reviews, Vol. 15.

Yuan, J. and R. Wu (2011), “China's Environmental Laws Receiving Greater Attention”, China Law and Practice, March 2011.

Zhang, Z. (2010), “Assessing China's Carbon Intensity Pledge for 2020: Stringency and Credibility Issues and their Implications", East-West Center Working Papers Economic Series, No. 113.

Zhang, H-D. and X-P. Zheng (2012), "Characteristics of Hazardous Chemical Accidents in China: A Statistical Investigation", Journal of Loss Prevention in the Process Industries, Vol. 25.

Zhang, J. (2012), "The Impact of Water Quality on Health: Evidence from the Drinking Water Infrastructure Program in Rural China”, Journal of Health Economics, Vol. 31.

Zhang, J., D. Mauzerall, T. Zhu, S. Liang, M. Ezzati and J. Remais (2010a), "Environmental Health in China: Progress Towards Clean Air and Safe Water", The Lancet, Vol. 375.

Zhang, S., X. Yang, Y. Jiang and Q. Wei (2010b), "Comparative Analysis of Energy use in China Building Sector: Current Status, Existing Problems and Solutions", Frontiers of Energy and Power Engineering in China, Vol. 4.

Zheng, S., J. Cao and M. Kahn (2011), "China's Rising Demand for 'Green Cities': Evidence from Crosscity Real Estate Price Hedonics”, NBER Working Papers, No. 16992.

Zhong, L. and A. Mol (2010), "Water Price Reforms in China: Policy-Making and Implementation", Water Resources Management, Vol. 24.

Zhou, Y. (2012), “China Responds to Fukushima”, Bulletin of the Atomic Scientists, June.

Zhou, Y., C. Rengifo, P. Chen and J. Hinze (2011), “Is China ready for its Nuclear Expansion?”, Energy Policy, Vol. 39. 
$\mathrm{ECO} / \mathrm{WKP}(2013) 37$

\section{WORKING PAPERS}

The full series of Economics Department Working Papers can be consulted at www.oecd.org/eco/workingpapers/

1044. Making the tax system less distortive in Switzerland

(April 2013) by Andrés Fuentes

1043. The determinants of informality in Mexico's states

(April 2013) by Sean M. Dougherty and Octavio Escobar

1042. Legal reform, contract enforcement and firm size in Mexico

(April 2013) by Sean M. Dougherty

1041. Improving the economic situation of young people in France

(April 2013) by Hervé Boulhol

Améliorer la situation économique des jeunes en France

(avril 2013) par Hervé Boulhol

1040. Improving employment prospects for young workers in Spain

(April 2013) by Anita Wölfl

1039. Youth labour market performance in Spain and its determinants - a micro-level perspective

(April 2013) by Juan J. Dolado, Marcel Jansen, Florentino Felgueroso, Andres Fuentes and Anita Wölfl

1038. The efficiency and equity of the tax and transfer system in France

(April 2013) by Balázs Égert

Efficacité et équité du système de prélèvements et de transferts en France

(avril 2013) par Balázs Égert

1037. Income inequality and poverty in Colombia. Part 2. The redistributive impact of taxes and transfers

(April 2013) by Isabelle Joumard and Juliana Londoño Vélez

1036. Income inequality and poverty in Colombia. Part 1. The role of the labour market

(April 2013) by Isabelle Joumard and Juliana Londoño Vélez

1035. Policy options to durably resolve euro area imbalances

(March 2013) by Yvan Guillemette and Dave Turner

1034. Labour market, welfare reform and inequality in the United Kingdom

(March 2013) by Christophe André, Clara Garcia, Giulia Giupponi and Jon Kristian Pareliussen

1033. Work incentives and Universal Credit - reform of the benefit system in the United Kingdom

(March 2013) by Jon Kristian Pareliussen

1032. Strengthening social cohesion in Luxembourg: making efficiency and equity go hand in hand

(March 2013) by Jean-Marc Fournier and Clara Garcia

1031. The price of oil - Will it start rising again?

(March 2013) by Jean-Marc Fournier, Isabell Koske, Isabelle Wanner and Vera Zipperer 
1030. The system of revenue sharing and fiscal transfers in China

(February 2013) by Xiao Wang and Richard Herd

1029. The declining competitiveness of French firms reflects a generalised supply-side problem (February 2013) by Hervé Boulhol and Patrizio Sicari

1028. Do the overall level and dispersion of socio-economic background measures explain France's gap in PISA scores?

(February 2013 by Hervé Boulhol and Patrizio Sicari

1027. Labour market performance by age groups: a focus on France

(February 2013) by Hervé Boulhol and Patrizio Sicari

1026. Moving towards a single labour contract: pros, cons and mixed feelings

(February 2013) by Nicolas Lepage-Saucier, Juliette Schleich and Etienne Wasmer

1025. Boosting productivity in Australia

(January 2013) by Vassiliki Koutsogeorgopoulou and Omar Barbiero

1024. Housing, financial and capital taxation policies to ensure robust growth in Sweden (January 2013) by Müge Adalet McGowan

1023. Labour market and social policies to foster more inclusive growth in Sweden (January 2013) by Stéphanie Jamet, Thomas Chalaux and Vincent Koen

1022. Educational attainment and labour market outcomes in South Africa, 1994-2010 (January 2013) by Nicola Branson and Murray Leibbrandt

1021. Education quality and labour market outcomes in South Africa

(January 2013) by Nicola Branson and Murray Leibbrandt

1020. Do policies that reduce unemployment raise its volatility? Evidence from OECD countries (January 2013) by Alain de Serres and Fabrice Murtin

1019. Slovakia: A catching up euro area member in and out of the crisis (January 2013) by Jarko Fidrmuc, Caroline Klein, Robert Price and Andreas Wörgötter

1018. Improving the fiscal framework to enhance growth in an era of fiscal consolidation in Slovakia (January 2013) by Caroline Klein, Robert Price and Andreas Wörgötter

1017. Investing efficiently in education and active labour market policies in Slovakia (January 2013) by Caroline Klein

1016. The performance of road transport infrastructure and its links to policies (January 2013) by Henrik Braconier, Mauro Pisu and Debra Bloch

1015. The US labour market recovery following the great recession (January 2013) by Wendy Dunn

1014. Why do Russian firms use fixed-term and agency work contracts? (December 2012) by Larisa Smirnykh and Andreas Wörgötter 